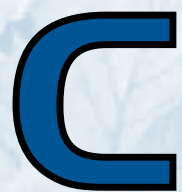

Septembre 2011 • Volume 37 • DCC-4

ISSN 1188-4169

Une déclaration d'un comité consultatif (DCC)

Comité consultatif national de l'immunisation (CCNI) ${ }^{\dagger}$

\title{
Addendum à la déclaration sur le vaccin inactivé trivalent contre l'in luenza saisonnière
}

\section{Recommandations concernant l'utilisation du vaccin antigrippal trivalent inactivé intradermique (VTH-D)}

\section{Préambule}

Le Comité consultatif national de l'immunisation (CCNI) donne à l'Agence de la santé publique du Canada des conseils constants et à jour liés à l’immunisation dans le domaine de la médecine, des sciences et de la santé publique. L'Agence de la santé publique du Canada reconnaît que les conseils et les recommandations figurant dans le présent document reposent sur les connaissances scientifiques les plus récentes et diffuse ce document à des fins d'information. Les personnes qui administrent le vaccin doivent également connaître le contenu de la ou des monographies de produit pertinentes. Les recommandations d'utilisation et les autres renseignements qui figurent dans le présent document peuvent différer du contenu des monographies de produit établies par le ou les fabricants du vaccin au Canada. Les fabricants ont fait approuver le vaccin et en ont démontré l'innocuité et l'efficacité uniquement lorsqu'ils sont utilisés conformément à la ou aux monographies de produit. Les membres du CCNI et les agents de liaison doivent se conformer à la politique de l'Agence de la santé publique du Canada régissant les conflits d'intérêts, notamment de déclarer chaque année les conflits d’intérêts possibles.

†La présente déclaration a été rédigée par Tara Harris et la Dre Nadine Sicard et a été approuvée par le CCNI.

†Membres du CCNI : Dre J. Langley (présidente), Dre B. Warshawsky (vice-présidente), Dr C. Cooper, Dre N. Crowcroft , M ${ }^{\text {me }}$ A. Hanrahan, Dre B. Henry , Dre D Kumar, Dre S. McNeil , D B. Seifert, Dre C. Quach-Thanh, Dre D. Skowronski, Dre W. Vaudry, Dr R. Warrington

Représentants de liaison : A. Mawle (Centres de prévention et de lutte contre les maladies), Dr J. Brophy (CAIRE), Dr H. Morrison (Conseil des médecins hygiénistes en chef), Mme K. Pielak (Coalition canadienne des infirmières et infirmiers pour l'immunisation), D ${ }^{\text {re }}$ S. Rechner (Collège des médecins de famille du Canada), D ${ }^{\text {re }}$ M. Salvadori (Société canadienne de pédiatrie), D ${ }^{\text {re }}$ S. Pelletier (Association pour la prévention des infections à l'hôpital et dans la communauté-Canada), Dre N. Sicard (Association canadienne de santé publique), Dre V. Senikas (Société des obstétriciens et gynécologues du Canada), Dr P. Plourde (Comité consultatif de la médecine tropicale et de la médecine des voyages)

Représentants d'office : Dre B. Law (Centre de l'immunisation et des maladies respiratoires infectieuses), Lcol (Dr) James Anderson (ministère de la Défense nationale), Dre Ezzat Farzad (Direction générale de la santé des Premières nations et des Inuits - Bureau de la médecine communautaire), Dr P. Varughese (Centre de l'immunisation et des maladies respiratoires infectieuses), Dr J. A. Laroche (Centre de l'immunisation et des maladies respiratoires infectieuses), Dre A. Klein (Direction des produits biologiques et des thérapies génétiques, Santé Canada), Joanne Xiong (Direction des produits biologiques et des thérapies génétiques, Santé Canada)

Autres membres du groupe de travail sur l'influenza : Dr P. Van Buynder (Comité canadien d'immunisation), Dre B. Cholin (région sanitaire du Nord des Prairies), Dr S. Halperin (Départements de microbiologie et d'immunologie et de pédiatrie, Centre canadien de vaccinologie, Université Dalhousie), Dr I. Gemmill (circonscription sanitaire de Kingston, Frontenac et Lennox), Dr G. DeSerres (Institut national de santé publique du Québec et Faculté de médecine de l'Université Laval) 


\section{Introduction}

En mai 2010, un vaccin antigrippal trivalent inactivé administré par voie intradermique (VTI-ID) (Intanza ${ }^{\circledR}$, Sanofi Pasteur)(1) a été homologué au Canada pour l'immunisation active des adultes âgés de plus de 18 ans contre l'influenza causée par les souches grippales spécifiques contenues dans le vaccin.

Le présent supplément à la Déclaration sur le vaccin trivalent inactivé (VTI) contre l'influenza pour la saison 2010-2011 du CCNI vise à :

- donner un bref aperçu des recommandations du CCNI concernant l'utilisation du VTI pour la saison 2010-2011;

- donner de l'information sur le VTI-ID récemment homologué $\left(\operatorname{Intanz} \mathrm{a}^{\circledR}\right)$, qui est administré par micro-injection;

- formuler des recommandations touchant l'utilisation d'Intanza ${ }^{\circledR}$.

Pour plus de détails sur l'épidémiologie de l'influenza et les personnes pour lesquelles le vaccin antigrippal est recommandé pour la saison 2010-2011, veuillez consulter la Déclaration sur le vaccin trivalent inactivé (VTI) contre l'influenza pour la saison 2010-2011, qui est accessible en ligne à l'adresse suivante : http://www.phac-aspc.gc.ca/publicat/ ccdr-rmtc/10vol36/acs-6/index-fra.php.

\section{Recommandations}

- Le CCNI recommande d'utiliser Intanza ${ }^{\circledR}(9 \mu \mathrm{g} /$ souche) pour la prévention de l'influenza chez les adultes bien portants âgés de 18 à 59 ans. (Recommandation du CCNI de catégorie A)

- Le CCNI recommande d'utiliser Intanza ${ }^{\circledR}(9 \mu \mathrm{g} /$ souche) pour la prévention de l'influenza chez les adultes âgés de 18 à 59 ans atteints d'une affection chronique, à savoir le diabète ou une maladie cardiaque, pulmonaire, rénale ou neurologique. (Recommandation du CCNI de catégorie B)
- Le CCNI recommande de considérer l'usage d'Intanza ${ }^{\circledast}(15 \mu \mathrm{g} /$ souche) pour la prévention de l'influenza chez les adultes âgés de 18 à 59 ans atteints d'un déficit immunitaire. (Recommandation du CCNI de catégorie I)

- Le CCNI recommande d'utiliser Intanza ${ }^{\circledR}(15 \mu \mathrm{g} /$ souche) pour la prévention de l'influenza chez les adultes âgés de 60 ans et plus. (Recommandation du CCNI de catégorie A)

- À l'heure actuelle, le CCNI est d'avis que les données probantes sont insuffisantes pour formuler une recommandation concernant l'usage préférentiel d'Intanza ${ }^{\circledR}$ plutôt que d'autres VTI homologués au Canada. (Recommandation du CCNI de catégorie I)

Linjection intradermique est depuis longtemps considérée comme une voie d'immunisation potentiellement viable. Bien qu'elle soit couramment utilisée pour l'administration du vaccin contre la rage, du vaccin bacille Calmette-Guérin (BCG) et du vaccin contre l'hépatite B (mais non au Canada), son usage est limité par la variabilité des réponses immunitaires qu'elle induit et par sa difficulté d'exécution(2).

Les vaccins antigrippaux administrés par voie cutanée ont récemment fait l'objet d'un intérêt renouvelé étant donné leur facilité d'accès, les économies de doses possibles et les caractéristiques immunologiques propres à la peau qui pourraient accroître la réponse immunitaire, particulièrement chez les personnes les plus vulnérables aux complications de linfluenza (2,3). De plus, des percées récentes dans les méthodes d'injection intradermique, à savoir les systèmes de micro-aiguilles, permettent d'éliminer les problèmes associés à la technique de Mantoux, qui est la méthode conventionnelle d'injection intradermique(4).

Intanza ${ }^{\circledR}$ est le premier VTI-ID homologué au Canada. 


\section{Aperçu des recommandations concernant l'utilisation du VTI pour la saison 2010-2011}

Le vaccin trivalent saisonnier pour 2010-2011 intègre la souche pandémique du virus de l'influenza A (pH1N1) de 2009, une nouvelle composante de l'influenza A (H3N2) et la même composante de l'influenza de type B qu'en 2009-2010

Les recommandations du CCNI pour la saison 2010-2011 portent sur l'utilisation de quatre vaccins homologués au Canada qui sont conçus pour être injectés par voie intramusculaire : Fluviral ${ }^{\circledR}$ (GlaxoSmithKline), Vaxigrip ${ }^{\circledR}$ (Sanofi Pasteur), Agriflu ${ }^{\circledR}$ (Novartis) et Influvac ${ }^{\circledast}$ (Abbott). Depuis la publication de ces recommandations, quatre autres vaccins ont été homologués au Canada, à savoir : Intanza $^{\circledR}$ et Fluzone ${ }^{\circledR}$ (Sanofi Pasteur), Fluad ${ }^{\circledR}$ (Novartis) et FluMist ${ }^{\circledR}$ (AstraZeneca). Les recommandations concernant l'utilisation de ces produits seront présentées dans des suppléments distincts. Pour la saison grippale 2010-2011, le

\section{Méthodologie}

Les détails sur le processus d'élaboration des déclarations du CCNI fondé sur des données probantes figurent dans le document Recommandations pour l'immunisation fondées sur des données probantes - Méthodes du Comité consultatif national de l'immunisation (RMTC, janvier 2009), qui est accessible en ligne à l'adresse suivante : http://www.phac-aspc.gc.ca/ publicat/ccdr-rmtc/09vol35/acs-1/index-fra.php.

Le CCNI a examiné les principales questions visées par l'examen documentaire proposé par le groupe de travail sur l'influenza, en l'occurrence le fardeau de la maladie à prévenir ainsi que la ou les populations cibles, l'innocuité, l'immunogénicité, l'efficacité des vaccins, les calendriers de vaccination et d'autres aspects de la stratégie globale d'immunisation. La synthèse des connaissances a été
CCNI recommande toujours aux programmes de vaccination de cibler les personnes qui présentent un risque élevé de complications liées à l'influenza, celles qui pourraient leur transmettre l'influenza et celles qui fournissent des services communautaires essentiels. De plus, le CCNI recommande que trois groupes additionnels qui ont présenté des taux d'incidence plus élevés de complications graves durant les deux vagues de la pandémie de l'influenza attribuable au virus pH1N1 soient considérés comme des candidats prioritaires pour recevoir le vaccin antigrippal. Ces nouveaux groupes sont constitués des personnes atteintes d'obésité morbide, les Autochtones et les enfants âgés de 2 à 4 ans.

Pour plus de détails concernant les personnes auxquelles le vaccin antigrippal est recommandé pour la saison 2010-2011, veuillez consulter la Déclaration sur le vaccin trivalent inactivé (VTI) contre l'influenza pour la saison 2010-2011, qui est accessible en ligne à l'adresse suivante : http://www.phac-aspc.gc.ca/publicat/ccdr-rmtc/10vol36/ acs-6/index-fra.php.

effectuée par $\mathrm{M}^{\mathrm{me}}$ Tara Harris et supervisée par le groupe de travail sur l'influenza. À la suite de l'évaluation critique des études individuelles, des tableaux sommaires contenant des cotes de qualité des données probantes ont été préparés en utilisant la hiérarchie méthodologique du CCNI (tableau 6) et des propositions de recommandations pour l'utilisation du vaccin ont été formulées. Le 9 février 2011, la présidente du groupe de travail ( $\mathrm{D}^{\text {re }}$ Nadine Sicard) a présenté les données probantes et proposé des recommandations au CCNI. À la suite de l'examen approfondi des données probantes et de la consultation lors de la réunion du CCNI du 9 février 2011, le comité s'est prononcé par vote sur des recommandations précises. Les considérations pertinentes, la justification des décisions particulières et les lacunes en matière de connaissances sont décrites dans le texte. 


\section{III. Épidémiologie}

Les déclarations antérieures du CCNI sur le vaccin trivalent inactivé (VTI) contre l'influenza décrivent l'épidémiologie de l'influenza. Un résumé concernant le virus pandémique pH1Nl de 2009 est présenté dans la déclaration de 2010-2011 sur le VTI.

\section{Vaccin}

\section{IV.1. Préparation(s) homologuée(s) au Canada (p. ex., description, composition)}

Intanza ${ }^{\circledR}$ (vaccin antigrippal [à virion fragmenté, inactivé]) est une suspension stérile, incolore et opalescente, préparée à partir de trois souches de virus de l'influenza. Le type d'antigènes viraux contenus dans Intanza ${ }^{\circledR}$ est conforme aux exigences actuelles de l'Organisation mondiale de la Santé (OMS). Les souches pour la saison 2010-2011 sont une souche analogue à A/California/7/2009 (H1N1), une souche analogue à A/Perth/16/2009 (H3N2) et la souche B/ Brisbane/60/2008(5).

Intanza ${ }^{\circledR}$ est offert en deux concentrations différentes. Chaque dose de $0,1 \mathrm{~mL}$ contient 9 ou $15 \mu \mathrm{g}$ d'hémagglutinine de virus grippal de chacune des souches; ces concentrations sont destinées aux adultes âgés de 18 à 59 ans et aux adultes âgés de 60 ans et plus, respectivement. Les résidus du processus de fabrication, à savoir la néomycine, le formaldéhyde, l'ovalbumine et Triton ${ }^{\circledR} \mathrm{X}-100$, peuvent être présents à l'état de traces. Intanza ${ }^{\circledR}$ ne contient pas de thimérosal. Le système de micro-injection ne contient aucun élément contenant du latex ou de dérivés du latex.

Intanza ${ }^{\circledR}$ est fabriqué selon le même procédé que Vaxigrip ${ }^{\circledR}$, un autre VTI de Sanofi Pasteur qui est homologué au Canada et administré par voie intramusculaire (IM).

\section{IV.2. Efficacité}

À l'heure actuelle, aucune étude n'a été publiée concernant l'efficacité d'Intanza ${ }^{\circledast}$. L'efficacité des vaccins antigrippaux inactivés en général est détaillée dans la déclaration de 2010-2011 sur le VTI(5), mais les données présentées se rapportent à des VTI administrés par voie IM seulement. En règle générale, on estime que si le vaccin antigrippal est bien assorti, son administration par voie IM prévient l'influenza chez $73 \%$ (intervalle de confiance [IC] à $95 \%$ : 54 - 84) des adultes bien portants(6) et $58 \%$ (IC à $95 \%$ : 34 - 73) des personnes âgées(7). En l'absence d'un bon assortiment, l'efficacité est estimée à $44 \%$ (IC à $95 \%$ : 23 - 59) chez les adultes bien portants(6). Des examens systématiques ont aussi montré que la vaccination antigrippale réduisait l'incidence des pneumonies, des hospitalisations et des décès chez les personnes âgées(7). Dans le passé, le CCNI a appelé à la prudence dans l'interprétation des résultats d'études observationnelles et a recommandé la tenue d'autres études pour évaluer la protection que confère le vaccin contre l'influenza confirmée en laboratoire et ses complications graves(5).

Il est généralement reconnu qu'un titre sérique d'anticorps inhibiteurs de l'hémagglutination (IH) de 1:40 présente une corrélation avec une protection de $50 \%$ contre l'infection et que les titres plus élevés (1:120-1:160) sont associés à une protection accrue pouvant atteindre $90 \%(8-11)$. Dans une publication récente, à l'aide d'une approche méta-analytique, Coudeville et ses collaborateurs(11) ont décrit la mise au point un modèle de protection clinique contre l'influenza confirmée en laboratoire pour tout titre d'anticorps IH. Ce modèle établit une relation positive significative entre le titre d'anticorps IH et la protection clinique qui reste constante indépendamment de la souche et du statut vaccinal. Dans une autre publication récente, Coudeville et ses collaborateurs(12) ont utilisé ce modèle ainsi que les résultats de deux essais cliniques(13, 14) afin de prédire l'efficacité, selon le profil d'immunogénicité des adultes âgés de 60 ans et plus, d'un vaccin antigrippal intradermique (ID) $\left(\right.$ Intanza ${ }^{\circledR}$ ) et d'un vaccin antigrippal intramusculaire (IM) (Vaxigrip ${ }^{\circledR}$ ). Selon les données mises en commun, l'efficacité prédite de la voie ID était de 63,3\% (IC à $95 \%$ : 
58,1 - 68,7) et celle de la voie IM était de 54,4\% (IC à $95 \%: 49,4$ - 59,2), ce qui représente un avantage relatif de 16,5\% (IC à $95 \%$ : 12,7 - 20,1) du vaccin ID par rapport au vaccin IM. Laugmentation relative prédite de l'efficacité chez les personnes âgées de 70 ans et plus était de 18,0 \% (IC à $95 \%$ : 12 - 24). Bien que ces données semblent indiquer qu'Intanza ${ }^{\circledR}$ présente des avantages cliniques potentiels, d'autres études sont nécessaires pour évaluer directement l'efficacité d'Intanza ${ }^{\circledR}$ contre l'influenza confirmée en laboratoire et ses complications graves.

\section{IV.3. Immunogénicité}

Les mécanismes exacts qui interviennent dans l'immunisation intradermique ne sont pas entièrement élucidés, mais il est établi que la peau contribue à des réponses immunitaires tant innées qu'adaptatives. Deux types de cellules présentatrices d'antigène professionnelles (cellules de Langerhans de l'épiderme et cellules dendritiques du derme) jouent un rôle crucial dans la réponse immunitaire innée de la peau et dans l'induction d'une réponse immunitaire adaptative contre les pathogènes $(2,3)$. Ces cellules dendritiques, présentes en fortes densités dans la peau, favorisent la capture rapide des antigènes par les vaisseaux lymphatiques et leur transport vers les ganglions lymphatiques. La migration des cellules dendritiques du derme vers les ganglions lymphatiques facilite l'activation/expansion des lymphocytes $\mathrm{T}$ et B dans les ganglions lymphatiques et l'induction de l'immunité humorale et cellulaire dirigée contre des antigènes spécifiques(3, 15, 16). Lantigène peut aussi être transporté vers les ganglions lymphatiques sans intervention des cellules dendritiques des tissus périphériques et être capté par les cellules dendritiques résidentes des ganglions lymphatiques ou encore être transféré aux cellules dendritiques résidentes par les cellules dendritiques migrantes de la peau, avec sensibilisation subséquente des lymphocytes T naifs(17).

Dans les essais cliniques portant sur Intanza ${ }^{\circledR}$, les titres moyens géométriques (TMG) d'anticorps IH étaient les principaux paramètres utilisés pour l'évaluation de la réponse immunitaire. On a comparé les TMG d'anticorps IH produits par Intanza ${ }^{\circledR}$ à ceux produits par un vaccin antigrippal IM. On a aussi évalué la réponse immunitaire induite par Intanza ${ }^{\circledR}$ en fonction des critères d'immunogénicité de l'Agence européenne des médicaments (EMEA) (veuillez consulter le tableau 1 ci-dessous)(18). Pour qu'un vaccin antigrippal donné fasse l'objet d'une homologation annuelle de l'EMEA pour des groupes d'âge prédéfinis, chacune de ses souches doit respecter au moins un des critères ci-dessous.. 


\section{Tableau 1 : Critères d'immunogénicité de l'Agence européenne des médicaments (EMEA) pour l'homologation annuelle des vaccins antigrippaux faisant appel aux méthodes de l'inhibition de l'hémagglutinine (IH) et de l'hémolyse radiale simple (HRS)(18)}

\begin{tabular}{|c|c|c|c|}
\hline \multirow[t]{2}{*}{ Critères } & \multirow[t]{2}{*}{ Définition } & \multicolumn{2}{|l|}{ Groupe d'âge } \\
\hline & & 18 à 60 ans & $>60$ ans \\
\hline $\begin{array}{l}\text { Séroconversion ou augmenta- } \\
\text { tion significative du titre }\end{array}$ & $\begin{array}{l}\text { Méthode de l'IH: } \\
\text { Pourcentage de sujets présentant un } \\
\text { titre de }<10 \text { avant la vaccination et de } \\
\geq 40 \text { après la vaccination } \\
\text { OU } \\
\text { Titre } \geq 10 \text { et accru par un facteur d'au } \\
\text { moins } 4 \text { du titre après la vaccination } \\
\text { Méthode de l'HRS: } \\
\text { Pourcentage de sujets présentant } \\
\text { un titre négatif avant la vaccination } \\
\text { et une surface } \geq 25 \mathrm{~mm}^{2} \text { après la } \\
\text { vaccination } \\
\text { OU } \\
\text { Augmentation de } \geq 50 \% \text { du titre } \\
\text { après la vaccination }\end{array}$ & $>40 \%$ & $>30 \%$ \\
\hline Séroprotection & $\begin{array}{l}\text { Pourcentage de sujets présentant un } \\
\text { titre d'anticorps mesuré par } \mathrm{IH} \geq 40 \\
\text { après la vaccination } \\
\text { OU } \\
\text { Titre d'anticorps mesuré par HRS } \\
>25 \mathrm{~mm}^{2}\end{array}$ & $>70 \%$ & $>60 \%$ \\
\hline $\begin{array}{l}\text { Augmentation de la moyenne } \\
\text { géométrique }\end{array}$ & $\begin{array}{l}\text { Rapport des TMG après et avant la } \\
\text { vaccination }\end{array}$ & $>2,5$ & $>2,0$ \\
\hline
\end{tabular}

\section{Adultes âgés de 18 à 59 ans}

Limmunogénicité d'Intanza ${ }^{\circledR}$ chez les adultes âgés de 18 à 59 ans est résumée à partir des essais cliniques de phase II et III menés par Beran et ses collaborateurs(19), Leroux-Roels et ses collaborateurs(20) (phase II) et Arnou et ses collaborateurs(21) (phase III).

Beran et ses collaborateurs(19) ont mené un essai de phase II multicentrique et randomisé visant à établir le dosage. Pour ce faire, ils ont comparé des doses de 3, 6 et $9 \mu \mathrm{g} /$ souche du vaccin antigrippal inactivé administré par micro-injection ID et une dose de $15 \mu \mathrm{g} /$ souche de vaccin antigrippal inactivé (Vaxigrip $^{\circledR}$ ) administré par voie IM. La dose de $6 \mu \mathrm{g} /$ souche du vaccin ID satisfaisait aux critères d'immunogénicité de l'EMEA, sauf en ce qui concerne la séroprotection et la séroconversion contre la souche B. En comparaison avec la préparation IM, les doses de 3 et $6 \mu \mathrm{g} / \mathrm{souche}$ du vaccin ID ne répondaient pas aux critères de non-infériorité (la limite inférieure de l'IC à $95 \%$ du rapport des TMG après la vaccination [ID/IM] était supérieure à 0,667 dans les deux groupes pour chaque souche). La réponse induite par la dose de $9 \mu \mathrm{g} /$ souche du vaccin ID était immunogène et 
satisfaisait aux critères de l'EMEA pour les trois souches; par conséquent, les essais subséquents ont porté exclusivement sur la dose de $9 \mu \mathrm{g} /$ souche du vaccin ID.

Les essais subséquents $(20,21)$ ont comparé Intanza ${ }^{\circledR}(9 \mu \mathrm{g} /$ souche) administré par micro-injection ID et Vaxigrip ${ }^{\circledR}$ (15 $\mathrm{gg}$ /souche) administré par voie IM. Tant dans l'essai réalisé par Leroux-Roels et ses collaborateurs(20) que dans celui réalisé par Arnou et ses collaborateurs(21), les titres avant la vaccination étaient comparables entre les groupes ID et IM pour les trois souches. Le statut immunologique antérieur était aussi comparable d'un groupe à l'autre dans les deux essais; la proportion de sujets n'ayant jamais reçu de vaccin antigrippal allait de 39,1 \% à 47,5\% .

Les paramètres primaires, en l'occurrence les TMG propres à chaque souche 21 jours après la vaccination, ont été évalués selon une approche de non-infériorité. L'immunogénicité était considérée comme non inférieure si la limite inférieure de l'IC à 95 \% de la différence des TMG log-transformés après la vaccination entre les groupes ID et IM était supérieure à -0,176 $\left(\log _{10}\left(\mathrm{TMG}_{\mathrm{ID}}\right)-\log _{10}\left(\mathrm{TMG}_{\mathrm{IM}}\right)>-0,176\right)$ pour les trois souches. Limmunogénicité était considérée comme statistiquement supérieure pour une souche donnée si la limite inférieure de l'IC à $95 \%$ de la différence des TMG log-transformés après la vaccination entre les groupes ID et IM était supérieure à $0\left(\log _{10}\left(\mathrm{TMG}_{\mathrm{ID}}\right)-\log _{10}\left(\mathrm{TMG}_{\mathrm{IM}}\right)>0\right)$.
Dans les deux essais, 21 jours après la vaccination, Intanza ${ }^{\circledR}$ satisfaisait aux trois critères de l'EMEA et était non inférieur à Vaxigrip ${ }^{\circledR}$ pour chacune des trois souches (A/H1N1, A/H2N3 et B). Les limites inférieures (correspondant à la définition de non-infériorité ci-dessus) se situaient à 0,006 et -0,084 pour la souche $\mathrm{A} / \mathrm{H} 1 \mathrm{~N} 1$, à 0,087 et $-0,059$ pour la souche $\mathrm{A} /$ H3N2 et à -0,003 et -0,064 pour la souche B dans les essais menés par Leroux-Roels et ses collaborateurs(20) et par Arnou et ses collaborateurs(21), respectivement.

Dans l'essai mené par Leroux-Roels et ses collaborateurs(20), les taux de séroprotection, les taux de séroconversion et les rapports des TMG étaient tous plus élevés dans le groupe ID que dans le groupe IM et la supériorité statistique du vaccin ID a été démontrée à l'égard des deux souches A (H1N1 et H3N2), mais non de la souche B. La persistance des anticorps a été évaluée à 3, 6 et 12 mois. Les taux de séroprotection dans le groupe ID étaient de $82 \%, 98 \%$ et $61 \%$ à 6 mois et de $68 \%, 96 \%$ et $50 \%$ à 12 mois pour les souches $\mathrm{A} / \mathrm{H} 1 \mathrm{~N} 1, \mathrm{~A} / \mathrm{H} 3 \mathrm{~N} 2$ et $\mathrm{B}$, respectivement. Le profil cinétique des vaccins IM et ID était presque identique.

Dans l'essai mené par Arnou et ses collaborateurs(21), les taux de séroprotection, les taux de séroconversion et les rapports des TMG étaient comparables entre les groupes ID et IM. Toutefois, selon l'essai mené par Leroux-Roels et ses collaborateurs(20), cet essai n'a fait ressortir aucun taux constamment plus élevé ni aucune supériorité statistique dans le groupe ID. 
Tableau 2 : Immunogénicité d'Intanza ${ }^{\circledR}(9 \mu \mathrm{g} /$ souche $)$ chez les adultes âgés de 18 à 59 ans 21 jours après la vaccination $(1,20,21)$

\begin{tabular}{|c|c|c|c|c|c|}
\hline & \multirow{2}{*}{$\begin{array}{l}\text { Critère de } \\
\text { I'EMEA }\end{array}$} & \multicolumn{2}{|c|}{ Phase II } & \multicolumn{2}{|c|}{ Phase III } \\
\hline & & $\begin{array}{c}9 \mu \mathrm{g} \text { ID } \\
\mathrm{n}=381\end{array}$ & $\begin{array}{c}15 \mu \mathrm{g} I \mathrm{M} \\
\mathrm{n}=379\end{array}$ & $\begin{array}{c}9 \mu \mathrm{Ig} \text { ID } \\
n=1255\end{array}$ & $\begin{array}{l}15 \mu \mathrm{g} I M \\
n=421\end{array}$ \\
\hline \multicolumn{6}{|c|}{ A/H1N1 } \\
\hline $\begin{array}{l}\text { Séroprotection } \\
\text { (IC à } 95 \% \text { ) }\end{array}$ & $>70 \%$ & $\begin{array}{c}92,4 \% \\
(89,3-94,9) \\
\end{array}$ & $\begin{array}{c}88,8 \% \\
(85,3-91,8) \\
\end{array}$ & $\begin{array}{c}87,2 \% \\
(85,2-89,0)\end{array}$ & $\begin{array}{c}86,2 \% \\
(82,6-89,3) \\
\end{array}$ \\
\hline $\begin{array}{l}\text { Séroconversion } \\
\text { (IC à } 95 \% \text { ) }\end{array}$ & $>40 \%$ & $\begin{array}{c}74,3 \% \\
(69,7-78,7) \\
\end{array}$ & $\begin{array}{c}70,4 \% \\
(65,6-74,9) \\
\end{array}$ & $\begin{array}{c}57,5 \% \\
(54,7-60,2) \\
\end{array}$ & $\begin{array}{c}56,4 \% \\
(51,6-61,1) \\
\end{array}$ \\
\hline $\begin{array}{l}\text { Rapport des TMG } \\
\text { (IC à } 95 \% \text { ) } \\
\text { Après/avant la vaccination }\end{array}$ & $>2,5$ & $\begin{array}{c}16,2 \\
(13,7-19,2)\end{array}$ & $\begin{array}{c}13,8 \\
(11,6-16,4)\end{array}$ & $\begin{array}{c}9,17 \\
(8,33-10,1)\end{array}$ & $\begin{array}{c}9,71 \\
(8,19-11,5)\end{array}$ \\
\hline \multicolumn{6}{|c|}{ A/H3N2 } \\
\hline $\begin{array}{l}\text { Séroprotection } \\
\text { (IC à } 95 \% \text { ) }\end{array}$ & $>70 \%$ & $\begin{array}{c}99,7 \% \\
(98,6-100)\end{array}$ & $\begin{array}{c}98,7 \% \\
(97,0-99,6)\end{array}$ & $\begin{array}{c}93,5 \% \\
(92,0-94,8) \\
\end{array}$ & $\begin{array}{c}95,4 \% \\
(93,0-97,2)\end{array}$ \\
\hline $\begin{array}{l}\text { Séroconversion } \\
\text { (IC à } 95 \% \text { ) }\end{array}$ & $>40 \%$ & $\begin{array}{c}85,1 \% \\
(81,2-88,5)\end{array}$ & $\begin{array}{c}79,2 \% \\
(74,8-83,1)\end{array}$ & $\begin{array}{c}66,5 \% \\
(63,8-69,0)\end{array}$ & $\begin{array}{c}69,3 \% \\
(64,7-73,6)\end{array}$ \\
\hline $\begin{array}{l}\text { Rapport des TMG } \\
\text { (IC à } 95 \% \text { ) } \\
\text { Après/avant la vaccination }\end{array}$ & $>2,5$ & $\begin{array}{c}28,2 \\
(23,7-33,5)\end{array}$ & $\begin{array}{c}20,7 \\
(17,5-24,4)\end{array}$ & $\begin{array}{c}11,5 \\
(10,4-12,7)\end{array}$ & $\begin{array}{c}11,2 \\
(9,58-13,1)\end{array}$ \\
\hline \multicolumn{6}{|c|}{ B } \\
\hline $\begin{array}{l}\text { Séroprotection } \\
\text { (IC à } 95 \% \text { ) }\end{array}$ & $>70 \%$ & $\begin{array}{c}90,6 \% \\
(87,2-93,3)\end{array}$ & $\begin{array}{c}85,5 \% \\
(81,5-88,8)\end{array}$ & $\begin{array}{c}72,9 \% \\
(70,4-75,3)\end{array}$ & $\begin{array}{c}74,8 \% \\
(70,4-78,8)\end{array}$ \\
\hline $\begin{array}{l}\text { Séroconversion } \\
\text { (IC à } 95 \% \text { ) }\end{array}$ & $>40 \%$ & $\begin{array}{c}76,4 \% \\
(71,9-80,6)\end{array}$ & $\begin{array}{c}73,5 \% \\
(68,8-77,8)\end{array}$ & $\begin{array}{c}56,7 \% \\
(54,0-59,4) \\
\end{array}$ & $\begin{array}{c}60,8 \% \\
(56,0-65,4)\end{array}$ \\
\hline $\begin{array}{l}\text { Rapport des TMG } \\
\text { (IC à } 95 \% \text { ) } \\
\text { Après/avant la vaccination }\end{array}$ & $>2,5$ & $\begin{array}{c}12,1 \\
(10,5-13,8)\end{array}$ & $\begin{array}{c}10,8 \\
(9,6-12,3)\end{array}$ & $\begin{array}{c}6,39 \\
(5,96-6,84)\end{array}$ & $\begin{array}{c}6,63 \\
(5,90-7,46)\end{array}$ \\
\hline
\end{tabular}

$\mathrm{ID}=$ intradermique, $\mathrm{IM}=$ intramusculaire, $\mathrm{IC}=$ intervalle de confiance 


\section{Adultes âgés de 60 ans et plus}

Limmunogénicité d'Intanza ${ }^{\circledR}$ chez les adultes âgés de 60 ans et plus est résumée à partir des essais cliniques de phase II et III menés par Holland et ses collaborateurs(13) et par Arnou et ses collaborateurs(14), respectivement. Holland et ses collaborateurs(13) ont comparé deux concentrations d'Intanza ${ }^{\circledR}$ (15 et $21 \mu \mathrm{g} /$ souche) administré par voie ID avec Vaxigrip ${ }^{\circledR}(15 \mu \mathrm{g} /$ souche) administré par voie IM. Arnou et ses collaborateurs(14) ont comparé Intanza ${ }^{\circledR}(15 \mu \mathrm{g} /$ souche) avec Vaxigrip ${ }^{\circledR}(15 \mu \mathrm{g} /$ souche $)$ pendant trois années consécutives dans quatre groupes de traitement (ID-ID-ID, IM-ID-ID, IM-IM-ID et IM-IM-IM) répartis selon le vaccin reçu chaque année de l'essai.

Les titres avant la vaccination étaient comparables d'un groupe à l'autre pour les trois souches, aussi bien dans l'essai de phase II que dans celui de phase III.(13, 14). Le statut immunologique antérieur était aussi comparable d'un groupe à l'autre dans les deux essais, la proportion de sujets ayant été vaccinés contre l'influenza durant la dernière année allant de 79 à $85 \%$.

Les essais de phase II et III comportaient les critères d'exclusion suivants : déficit immunitaire congénital ou acquis; traitement immunosuppresseur au cours des 6 derniers mois; traitement de longue durée par des corticostéroïdes; affection chronique instable. Environ $40 \%$ des sujets de l'essai de phase II et $65 \%$ des sujets de l'essai de phase III présentaient au moins une affection augmentant le risque de complications de l'influenza (diabète ou maladie cardiaque, pulmonaire, rénale ou neurologique)(13, 14).

Les paramètres primaires étaient les TMG et les taux de séroprotection pour les trois souches 21 jours après la vaccination. Les résultats de l'immunogénicité était considérés non inférieurs si la limite inférieure de l'IC à $95 \%$ du rapport des TMG des groupes ID et IM $\left(\mathrm{TMG}_{\mathrm{ID}}: \mathrm{TMG}_{\mathrm{IM}}\right)$ était supérieure à 0,667 pour chaque souche OU si la différence des TMG log-transformés des groupes ID et IM était supérieure à $-0,176$ pour chaque souche. Dans l'essai mené par Holland et ses collaborateurs (13), la supériorité statistique était considérée comme démontrée si l'IC à $95 \%$ du rapport $\mathrm{TMG}_{\mathrm{ID}}: \mathrm{TMG}_{\mathrm{IM}}$ était $>1$ pour au moins deux souches. Arnou et ses collaborateurs(14) considéraient qu'il y avait supériorité statistique si la limite inférieure de l'IC à $95 \%$ de la différence des taux de séroprotection des groupes ID et IM était supérieure à 0 pour au moins deux souches.

Dans l'essai mené par Holland et ses collaborateurs(13), les deux vaccins ID ( 15 et $21 \mathrm{\mu g} /$ souche) ont satisfait aux critères d'immunogénicité de l'EMEA chez les adultes de $>60$ ans et leur non-infériorité et leur supériorité statistique ont été démontrées par rapport au vaccin IM. Les taux de séroprotection et de séroconversion et les rapports des TMG obtenus avec les concentrations de 15 et $21 \mu \mathrm{g} /$ souche de vaccin ID étaient significativement plus élevés que ceux obtenus avec le vaccin IM pour les trois souches, hormis la séroprotection associée à la souche $\mathrm{A} / \mathrm{H} 1 \mathrm{~N} 1$ dans le groupe traité par $15 \mu \mathrm{g} /$ souche de vaccin ID, qui n'était pas significative. Les rapports $\mathrm{TMG}_{\mathrm{ID}}: \mathrm{TMG}_{\mathrm{IM}}$ pour les concentrations de 15 et $21 \mu \mathrm{g} /$ souche étaient, respectivement : $1,517(1,285$ - 1,786) et 1,592 (1,368 $1,849)$ pour la souche A/H1N1; $1,702(1,419$ - 20,46) et $1,706(1,429$ - 2,037) pour la souche A/H3N2; 1,493 (1,276 - 1,746) et 1,406 (1,205 - 1,641) pour la souche B. Aucun effet notable n'a été observé dans l'analyse de la supériorité après l'ajout du statut immunologique comme covariable.

Dans l'essai mené par Arnou et ses collaborateurs(14), Intanza ${ }^{\circledR}$ (15 $\mu \mathrm{g} /$ souche) ID a satisfait aux critères de l'EMEA et s'est avéré non inférieur au vaccin IM de comparaison. Les limites inférieures (correspondant à la définition de non-infériorité ci-dessus) se sont situées à 0,038 pour la souche $\mathrm{A} / \mathrm{H} 1 \mathrm{~N} 1$, à 0,171 pour la souche $\mathrm{A} / \mathrm{H} 3 \mathrm{~N} 2$ et à 0,026 pour la souche B. La supériorité statistique a été démontrée pour les trois souches: les différences des taux de séroprotection (ID - IM) se situaient à 5,78 \% (2,74 - 9,08), $p=0,0003$ pour la souche $\mathrm{A} / \mathrm{H} 1 \mathrm{~N} 1$, à $5,49 \%(3,40-7,76)$, $p<0,0001$ pour la souche $\mathrm{A} / \mathrm{H} 3 \mathrm{~N} 2$ et à $6,60 \%(3,05$ - 10,1), $p=0,0003$ pour la souche B. Dans les analyses a posteriori visant à évaluer l'effet de l'âge sur la supériorité, la supériorité a été maintenue après répartition des sujets dans deux groupes d'âge (60-70 ans et $\geq 70$ ans) considérés séparément. 
Tableau 3 : Immunogénicité d'Intanza ${ }^{\circledR}(15 \mu \mathrm{g} /$ souche $)$ chez les adultes âgés de 60 ans et plus 21 jours après la vaccination* $(1,13,14)$

\begin{tabular}{|c|c|c|c|c|c|c|}
\hline & \multirow{2}{*}{$\begin{array}{l}\text { Critère de } \\
\text { I'EMEA }\end{array}$} & \multicolumn{3}{|c|}{ Phase II } & \multicolumn{2}{|c|}{ Phase III } \\
\hline & & $\begin{array}{l}15 \mu g \text { ID } \\
N=365\end{array}$ & $\begin{array}{l}21 \mu g \text { ID } \\
N=369\end{array}$ & $\begin{array}{l}15 \mu \mathrm{g} I \mathrm{M} \\
\mathrm{N}=363\end{array}$ & $15 \mu \mathrm{g}$ ID & $15 \mu \mathrm{g} I \mathrm{M}$ \\
\hline \multicolumn{7}{|c|}{ A/H1N1 } \\
\hline $\begin{array}{l}\text { Séroprotection } \\
\text { (IC à } 95 \% \text { ) }\end{array}$ & $>60 \%$ & $\begin{array}{c}77,5 \\
(72,9-81,7)\end{array}$ & s.o. & $\begin{array}{c}72,2 \\
(67,3-76,7)\end{array}$ & $\begin{array}{c}77,0 \\
(75,3-78,6)\end{array}$ & $\begin{array}{c}71,2 \\
(68,4-73,9)\end{array}$ \\
\hline $\begin{array}{l}\text { Séroconversion } \\
\text { (IC à } 95 \% \text { ) }\end{array}$ & $>30 \%$ & $\begin{array}{c}41,3 \\
(39,2-46,6)\end{array}$ & s.o. & $\begin{array}{c}22,3 \\
(18,1-26,9)\end{array}$ & $\begin{array}{c}38,7 \\
(36,8-40,6)\end{array}$ & $\begin{array}{c}30,0 \\
(27,3-32,9)\end{array}$ \\
\hline GMT (95\% CI) & s.o. & $\begin{array}{c}86,7 \\
(76,7-98,1)\end{array}$ & $\begin{array}{c}90,9 \\
(81,7,101)\end{array}$ & $\begin{array}{c}57,1 \\
(51,2-63,7)\end{array}$ & $\begin{array}{c}81,9 \\
(78,2-85,8)\end{array}$ & $\begin{array}{c}69,1 \\
(64,1-74,4)\end{array}$ \\
\hline $\begin{array}{l}\text { Rapport des TMG } \\
\text { (IC à } 95 \% \text { ) } \\
\text { Après/avant la } \\
\text { vaccination }\end{array}$ & $>2,0$ & $\begin{array}{c}3,73 \\
(3,28-4,24)\end{array}$ & s.o. & $\begin{array}{c}2,37 \\
(2,13-2,63)\end{array}$ & $\begin{array}{c}3,97 \\
(3,77-4,18)\end{array}$ & $\begin{array}{c}3,19 \\
(2,94-3,45)\end{array}$ \\
\hline \multicolumn{7}{|c|}{ A/H3N2 } \\
\hline $\begin{array}{l}\text { Séroprotection } \\
\text { (IC à } 95 \% \text { ) }\end{array}$ & $>60 \%$ & $\begin{array}{c}98,1 \\
(96,1-99,2)\end{array}$ & S.o. & $\begin{array}{c}93,4 \\
(90,3-95,7)\end{array}$ & $\begin{array}{c}93,3 \\
(92,3-94,3)\end{array}$ & $\begin{array}{c}87,8 \\
(85,7-89,7)\end{array}$ \\
\hline $\begin{array}{l}\text { Séroconversion } \\
\text { (IC à } 95 \% \text { ) }\end{array}$ & $>30 \%$ & $\begin{array}{c}42,3 \\
(36,2-46,6)\end{array}$ & S.o. & $\begin{array}{c}27,2 \\
(22,7-32,1)\end{array}$ & $\begin{array}{c}61,3 \\
(59,3-63,1)\end{array}$ & $\begin{array}{c}46,9 \\
(43,9-49,9)\end{array}$ \\
\hline $\begin{array}{l}\text { TMG } \\
\text { (IC à } 95 \text { \%) }\end{array}$ & s.o. & $\begin{array}{c}400 \\
(354-452)\end{array}$ & $\begin{array}{c}403 \\
(359-452)\end{array}$ & $\begin{array}{c}235 \\
(205-268)\end{array}$ & $\begin{array}{c}298 \\
(282-315)\end{array}$ & $\begin{array}{c}181 \\
(167-197)\end{array}$ \\
\hline $\begin{array}{l}\text { Rapport des TMG } \\
\text { (IC à } 95 \% \text { ) } \\
\text { Après/avant la vaccina- } \\
\text { tion }\end{array}$ & $>2,0$ & $\begin{array}{c}4,14 \\
(3,56-4,83)\end{array}$ & s.o. & $\begin{array}{c}2,68 \\
(2,36-3,04)\end{array}$ & $\begin{array}{c}8,19 \\
(7,68-8,74)\end{array}$ & $\begin{array}{c}5,35 \\
(4,87-5,88)\end{array}$ \\
\hline \multicolumn{7}{|c|}{ B } \\
\hline $\begin{array}{l}\text { Séroprotection } \\
\text { (IC à } 95 \% \text { ) }\end{array}$ & $>60 \%$ & $\begin{array}{c}84,7 \\
(80,6-88,2)\end{array}$ & S.o. & $\begin{array}{c}73,9 \\
(69,2-78,4) \\
\end{array}$ & $\begin{array}{c}55,7 \\
(53,7-57,6)\end{array}$ & $\begin{array}{c}49,1 \\
(46,0-52,1) \\
\end{array}$ \\
\hline $\begin{array}{l}\text { Séroconversion } \\
\text { (IC à } 95 \% \text { ) }\end{array}$ & $>30 \%$ & $\begin{array}{c}43,1 \\
(39,0-48,4)\end{array}$ & S.o. & $\begin{array}{c}29,9 \\
(25,2,34,8) \\
\end{array}$ & $\begin{array}{c}36,4 \\
(34,5-38,3)\end{array}$ & $\begin{array}{c}30,7 \\
(28,0-33,6) \\
\end{array}$ \\
\hline $\begin{array}{l}\text { TMG } \\
\text { (IC à } 95 \% \text { ) }\end{array}$ & S.o. & $\begin{array}{c}100 \\
(89,6-112)\end{array}$ & $\begin{array}{c}95,5 \\
(85,7,106)\end{array}$ & $\begin{array}{c}67,7 \\
(60,6-75,7)\end{array}$ & $\begin{array}{c}39,9 \\
(38,2-41,6)\end{array}$ & $\begin{array}{c}34,9 \\
(32,7-37,3)\end{array}$ \\
\hline $\begin{array}{l}\text { Rapport des TMG } \\
\text { (IC à } 95 \% \text { ) } \\
\text { Après/avant la vaccina- } \\
\text { tion }\end{array}$ & $>2,0$ & $\begin{array}{c}3,65 \\
(3,26-4,10)\end{array}$ & S.O. & $\begin{array}{c}2,69 \\
(2,43-, 2,98)\end{array}$ & $\begin{array}{c}3,61 \\
(3,47-3,76)\end{array}$ & $\begin{array}{c}3,04 \\
(2,85-3,24)\end{array}$ \\
\hline
\end{tabular}

ID = intradermique, IM = intramusculaire, $\mathrm{IC}=$ intervalle de confiance

S.o. = Valeurs non fournies par Arnou et ses collaborateurs (2009) ni par Sanofi Pasteur (2010).

* En cas de divergence entre les valeurs de la monographie de produit et de la publication correspondante, celles de la monographie de produit ont préséance. 
On a effectué une analyse approfondie des données de l'essai de phase III dans le but d'évaluer l'effet de l'absence de papule ou de liquide au point d'injection après l'administration du vaccin sur la réponse immunitaire à Intanza ${ }^{\circledR}$. La présence ou l'absence de ces facteurs n'a entraîné aucune variation des TMG après la vaccination(1).

En plus des essais ci-dessus comparant Intanza ${ }^{\circledR}$ et Vaxigrip ${ }^{\circledR}$, un essai randomisé de phase III a été mené sur des adultes de 65 ans et plus dans le but de comparer Intanza ${ }^{\circledR}$ et Fluad $^{\circledR}$, un vaccin antigrippal inactivé avec un adjuvant huile dans eau (MF59 ${ }^{\circledR}$ ) administré par voie IM(22). Cet essai faisait appel à deux méthodes d'évaluation de l'immunogénicité : l'inhibition de l'hémagglutinine (IH) et l'hémolyse radiale simple (HRS). Des échantillons ont été prélevés avant la vaccination et 21 jours après la vaccination. La non-infériorité a été définie comme une limite supérieure de $<1,5$ des IC à $95 \%$ des rapports des TMG après la vaccination (vaccin avec adjuvant/vaccin intradermique) pour les trois souches.

Intanza ${ }^{\circledR}$ a satisfait aux critères de non-infériorité fondés sur les TMG pour les trois souches selon la méthode de l'HRS et pour les souches H1N1 et B seulement selon la méthode de l'IH. Les rapports des TMG après la vaccination (Fluad ${ }^{\circledR} /$ Intanza $^{\circledR}$ ) selon les méthodes de l'IH et de l'HRS, respectivement, étaient : $1,13(0,95$ - 1,34) et $1,16(1,00$ $1,34)$ pour la souche $\mathrm{A} / \mathrm{H} 1 \mathrm{~N} 1 ; 1,31(1,13$ - 1,53) et 1,18 $(1,03$ - 1,34) pour la souche A/H3N2; $1,08(0,95-1,23)$ et $1.03(0,91-1,17)$ pour la souche B. La supériorité n'a pas été évaluée à l'aide de la méthode de l'IH (non-infériorité non établie pour les trois souches) et la supériorité a été évaluée par la méthode de l'HRS, sans toutefois avoir été établie pour aucune des souches. Une analyse a posteriori avec ajustement pour les titres d'anticorps de référence a démontré la non-infériorité du vaccin ID, tant par la méthode de l'IH que par la méthode de l'HRS, et ce pour les trois souches(22).

Aucune différence notable n'a été observée entre les deux groupes de vaccination sur le plan des rapports des TMG, des taux de séroprotection ni des taux de séroconversion, que ce soit par IH ou par HRS, hormis les taux de séroprotection associés à la souche $\mathrm{A} / \mathrm{H} 1 \mathrm{~N} 1$. Les taux de séroprotection étaient élevés dans les deux groupes de traitement, mais ils étaient significativement plus élevés dans le groupe traité par le vaccin avec adjuvant (différence de 5,8 \% [0,7 - 10,9] et de 5,8 \% [1,1 - 10,5], selon les méthodes de l'IH et de l'HRS, respectivement)(22).

Selon la méthode de l'IH, les deux vaccins satisfaisaient aux trois critères de l'EMEA pour les souches A/H1N1 et A/ H3N2, mais seulement au critère fondé sur le rapport des TMG pour la souche B. Selon la méthode de l'HRS, les deux vaccins satisfaisaient à tous les critères de l'EMEA pour les trois souches(22).

\section{Adultes atteints d'une affection chronique}

Cinq études publiées ont évalué l'utilisation du vaccin antigrippal administré par voie intradermique chez les personnes atteintes d'une affection chronique, y compris d'un déficit immunitaire, reconnue pour accroître le risque de complications de l'influenza (veuillez vous reporter au tableau 6). Dans quatre de ces études(23-26), la réponse anticorps induite par le vaccin ID était comparable à celle induite par le vaccin IM standard et aucun problème notable d'innocuité n'a été observé. Cependant, la variabilité du produit utilisé, la dose d'antigène dans le vaccin ID et le recours à la technique de technique de Mantoux limitent l'application des observations à Intanza ${ }^{\circledR}$.

Dans une étude descriptive de phase II, Morelon et ses collaborateurs(27) ont évalué l'immunogénicité et l'innocuité d'Intanza ${ }^{\circledR}$ chez des receveurs d'une greffe de rein ayant des antécédents de non-réponse à des vaccins antigrippaux conventionnels. Deux cent un receveurs adultes d'une greffe de rein ont été recrutés pour recevoir un vaccin antigrippal IM au cours de la saison grippale 2006-2007. De ce nombre, 62 sujets n'ayant pas répondu au vaccin ont été retenus et répartis aléatoirement parmi deux groupes, l'un traité par Intanza ${ }^{\circledR}(15 \mu \mathrm{g} /$ souche, ID) et

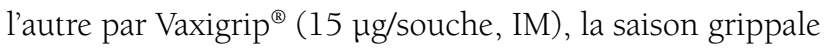
suivante (2007-2008). Dans cette population hyporéactive, Intanza ${ }^{\circledR}$ ID a été bien toléré et a entrainé des signes d'immunogénicité accrue comparativement à Vaxigrip ${ }^{\circledR}$ IM pour chacun des trois antigènes à l'étude. La réponse des anticorps 21 jours après la vaccination par Intanza ${ }^{\circledR}$ ID était conforme aux critères d'homologation de l'EMEA concernant l'homologation des vaccins contre l'influenza saisonnière destinés à cette population (sauf en ce qui concerne la 
taille de l'échantillon, qui comptait moins de 50 sujets), contrairement à la réponse des anticorps dans le groupe de comparaison traité par Vaxigrip ${ }^{\circledR}$. Les rapports des TMG et les taux de séroprotection et de séroconversion étaient généralement plus élevés dans le groupe ID, hormis le taux de séroconversion pour la souche B, qui était le même d'un groupe à l'autre. Dans le groupe ID, les rapports des TMG étaient supérieurs à 2,5 pour les souches $\mathrm{A} / \mathrm{H} 1 \mathrm{Nl}$ et $\mathrm{A} /$ H3N2 et les taux de séroprotection dépassaient $70 \%$ pour les souches $\mathrm{A} / \mathrm{H} 1 \mathrm{~N} 1$ et $\mathrm{B}$. Il importe de noter qu'on a utilisé des doses égales d'antigène ( $15 \mu \mathrm{g} /$ souche) pour le vaccin ID et le vaccin IM (vaccin ID préparé dans un volume réduit de $0,1 \mathrm{~mL}$ ), étant donné que les études antérieures dans cette population comparaient des doses réduites du vaccin antigrippal et des doses complètes du vaccin antigrippal IM.

Dans une analyse a posteriori, on a comparé des sujets de 60 ans et plus qui avaient participé à l'étude de phase III sur Intanza ${ }^{\circledR}$ selon qu'ils étaient atteints ou non d'une affection à risque élevé(28). Après l'administration d'Intanza ${ }^{\circledR}$, les taux de séroprotection chez les sujets atteints d'au moins une affection à risque (c.-à-d. diabète ou maladie cardiaque, pulmonaire, rénale ou neurologique) étaient semblables ou supérieurs à ceux chez les sujets bien portants $(77,2 \%$ vs $76,6 \%, 93,1 \%$ vs $93,7 \%$ et $58,7 \%$ vs $50,0 \%$ pour les souches H1N1, H3N2 et B, respectivement). Il importe de préciser que, pour les besoins de cette analyse, on a exclu les personnes atteintes d'une affection chronique instable (définie comme une affection ayant nécessité une hospitalisation ou un ajustement posologique cliniquement important durant les 12 dernières semaines) ou d'un déficit immunitaire congénital ou acquis, les personnes ayant subi un traitement immunosuppresseur durant les 6 derniers mois et les personnes suivant un traitement de longue durée par des corticostéroïdes systémiques(14).)

\section{IV.4. Administration du vaccin et calendrier}

\section{IV.4.1 Calendrier et posologie}

Le vaccin antigrippal annuel est administré en une dose. La posologie recommandée est de $0,1 \mathrm{~mL}$ ( $9 \mu \mathrm{g} /$ souche) chez les adultes âgés de 18 à 59 ans et de $0,1 \mathrm{~mL}$ (15 $\mu \mathrm{g} /$ souche) chez les adultes âgés de 60 ans et plus.

Intanza ${ }^{\circledR}$ n'est pas approuvé pour les personnes de moins de 18 ans.

\section{IV.4.2 Voie d'administration}

Intanza ${ }^{\circledR}$ est administré par voie ID. Le site d'injection recommandé est la région deltoïde. Intanza ${ }^{\circledR}$ est fourni dans un système de micro-injection pour administration intradermique qui consiste en une seringue préremplie munie d'une micro-aiguille ( $1,5 \mathrm{~mm})$ et d'un système de protection de l'aiguille destiné à recouvrir la micro-aiguille après usage.

Le système de micro-injection utilisé pour Intanza ${ }^{\circledR}$ (système de micro-injection BD SoluviaMD, entité pharmaceutique de BD Medical) a été évalué par Laurent et ses collaborateurs(4) à l'aide des modèles d'évaluation clinique suivants : imagerie du site d'injection (radiographie et ultrasonographie 3D), examen histologique des points d'injection, mesure de l'exactitude du volume d'injection, douleur ressentie par le sujet et réactivité cutanée locale. Le système de micro-injection BD SoluviaMD permet d'injecter correctement la dose dans la région deltoïde sous le derme, et la longueur d'aiguille de 1,5 $\mathrm{mm}$ a été validée dans une vaste population multiethnique constituée d'adultes ( $\mathrm{n}=$ 645)(4).

\section{IV.5. Conditions d'entreposage}

Intanza ${ }^{\circledR}$ doit être conservé à une température de $2{ }^{\circ} \mathrm{C}$ à $8{ }^{\circ} \mathrm{C}$ et ne doit pas être congelé. (hémolyse radiale simple 1)

\section{IV.6. Administration simultanée avec d'autres vaccins}

Aucune étude n'a porté sur l'administration simultanée d'Intanza ${ }^{\circledR}$ avec d'autres vaccins. Le CCNI est d'avis que, en général, le vaccin contre l'influenza peut être donné en même temps que d'autres vaccins, idéalement dans des membres opposés. Si les injections sont administrées dans le même membre, il faut choisir des points différents. On doit utiliser des aiguilles et des seringues différentes.

Il y a un chevauchement considérable des groupes pour lesquels le vaccin contre l'influenza et le vaccin polysaccharidique contre le pneumocoque sont recommandés. Lorsqu'ils administrent le vaccin antigrippal, les professionnels de la santé devraient en profiter pour vacciner contre le pneumocoque les personnes admissibles conformément au Guide canadien d'immunisation (GCI, 2006 : http://www.phac-aspc.gc.ca/publicat/cig-gci/index-fra.php). 


\section{IV.7. Effets secondaires}

Un sommaire détaillé des effets secondaires liés au vaccin antigrippal inactivé figure dans la Déclaration du CCNI sur le VTI pour 2010-2011(5). Les données sur les effets secondaires survenus dans les essais cliniques pré-commercialisation d'Intanza ${ }^{\circledR}$ sont résumées ci-dessous.

Chez les adultes âgés de 18 à 59 ans et de 60 ans et plus, les réactions systémiques à l'administration d'Intanza ${ }^{\circledR}$ étaient comparables à celles associées au vaccin IM de comparaison dans les quatre essais $(13,14,20,21)$. Les réactions au point d'injection étaient toujours plus nombreuses et plus importantes dans les groupes traités par le vaccin ID; en général, elles apparaissaient le lendemain de la vaccination et duraient 3 jours avant de se résoudre spontanément.

Dans un essai randomisé contrôlé visant des adultes âgés de 18 à 59 ans(20), les réactions sollicitées au point d'injection (érythème, induration et enflure) dans les sept jours suivant l'immunisation étaient plus nombreuses chez les receveurs du vaccin ID que chez les receveurs du vaccin IM. L'érythème a été la réaction la plus souvent signalée au point d'injection : 9,6\% des receveurs du vaccin ID et 0,8\% des receveurs du vaccin IM ont présenté un érythème de $5 \mathrm{~cm}$ de diamètre ou plus. Un érythème durant plus de 4 jours a été observé chez $44 \%$ des receveurs du vaccin ID contre 1,3\% des receveurs du vaccin IM. Le nombre de réactions systémiques était comparable entre les deux groupes, sauf en ce qui a trait à la myalgie, qui a touché davantage de receveurs du vaccin IM que de receveurs du vaccin ID (29,4\% vs 19,7\%, respectivement).

Lessai de phase III mené chez des adultes âgés de 18 à 59 ans a donné des résultats semblables(21). Les cas d'érythème ( $84,4 \%$ vs $25,5 \%$ ), d'enflure (61,9\% vs $20,7 \%$ ), d'induration ( $60,8 \%$ vs $26,1 \%$ ) et de prurit $(44,8 \%$ vs $13,1 \%$ ) étaient plus nombreux dans le groupe ID que dans le groupe IM, tandis que les cas de douleur semblaient plus fréquents dans le groupe IM que dans le groupe ID (48,4\% vs $43,1 \%$ ). La plupart des réactions au point d'injection sont apparues le lendemain de la vaccination et étaient résolues le jour 4. Comme dans l'essai randomisé contrôlé mené par Leroux-Roels et ses collaborateurs(20), le nombre de réactions systémiques était comparable entre les groupes ID et IM, sauf en ce qui a trait à la myalgie, qui a touché un peu plus de sujets du groupe IM que du groupe ID (29,5\% vs $23,5 \%)(21)$.

Le profil d'évènements indésirables chez les adultes âgés de 60 ans et plus était semblable à celui établi chez les adultes plus jeunes dans les études ci-dessus. Durant la phase II, les cas d'érythème ( 78,8 \% vs 19,1\%), d'enflure (62,2 \% vs $13,4 \%$ ), d'induration $(64,6 \%$ vs $16,7 \%$ ) et de prurit $(27,7 \%$ vs $8,7 \%)$ au point d'injection 7 jours après la vaccination étaient plus nombreux chez les sujets traités par Intanza ${ }^{\circledR} 15 \mu \mathrm{g}$ ID que chez ceux traités par Vaxigrip ${ }^{\circledR} 15 \mu \mathrm{g}$ $\operatorname{IM}(13)$. Le nombre de réactions indésirables systémiques était également semblable d'un groupe à l'autre : 30,2 \% des sujets du groupe ID ont présenté au moins une réaction systémique, comparativement à 27,4\% des sujets du groupe IM. Les maux de tête ont été la principale réaction observée dans les deux groupes (18,1\% dans le groupe ID vs 7,4 \% dans le groupe IM).

Les réactions au point d'injection observées durant la phase III étaient constantes. Le nombre de cas de prurit, d'érythème $(32,5 \mathrm{~cm}$ et $>5 \mathrm{~cm}$ ), d'enflure et d'induration était plus élevé dans le groupe ID, tandis que le nombre de cas d'ecchymoses était comparable d'un groupe à l'autre. Ces réactions duraient généralement moins de trois jours; moins de $1 \%$ des sujets dans l'un ou l'autre des groupes ont présenté des réactions durant plus de trois jours(14). Comme cette étude portait sur trois années consécutives, il a été possible d'évaluer la réactogénicité après deux et trois années d'administration du vaccin ID. Le taux de réactions au point d'injection semblait plus élevé dans le groupe traité par le vaccin ID trois années consécutives (ID-ID-ID), (71,3\%, IC à $95 \%: 69,4-73,2)$ que dans ceux traités par le vaccin deux années (IM-ID-ID) $(67,4 \%$, IC à $95 \%: 62,9$ - 71,6) ou une année (IM-IM-ID) (57,3\%, IC à $95 \%$ : 50,6 - 63,8). Cependant, le taux global du groupe ID-ID-ID était inférieur à celui observé chez l'ensemble des sujets ayant reçu le vaccin ID la première année de l'étude (77,9\%). Aucune différence importante n'a été notée sur le plan des réactions systémiques entre les groupes ID et IM. Dans les deux groupes, les maux de tête, les myalgies et les malaises étaient les principaux événements indésirables déclarés. 
Les données mises en commun de quatre essais cliniques (de phase II et III) sont présentées ci-dessous. Ces essais visaient des adultes âgés de 18 à 59 ans et de 60 ans et plus; de ceux-ci, 2384 et 2 974, respectivement, ont reçu Intanza ${ }^{\circledR}$ et $15 \mu \mathrm{g}$, et 843 et 1458 , respectivement, ont reçu le vaccin de comparaison Vaxigrip ${ }^{\circledast}(15 \mu \mathrm{g})$.

Tableau 4 : Réactions au point d'injection et réactions systémiques chez des adultes âgés de 18 à 59 ans vaccinés par Intanza ${ }^{\circledR}(9 \mu \mathrm{g})$ et chez des adultes âgés de 60 ans et plus vaccinés par Intanza ${ }^{\circledR}(15 \mu \mathrm{g})$ comparativement à des sujets vaccinés par Vaxigrip ${ }^{\circledR}(15 \mu \mathrm{g})$; données mises en commun des essais cliniques de phase II et $\mathrm{III}(1,13,14,20,21)$

\begin{tabular}{|c|c|c|c|c|}
\hline \multirow[t]{2}{*}{ Symptômes } & \multicolumn{2}{|c|}{$\begin{array}{c}\text { Adultes } \\
18-59 \text { ans }\end{array}$} & \multicolumn{2}{|c|}{$\begin{array}{c}\text { Adultes } \\
60 \text { ans et plus }\end{array}$} \\
\hline & $\begin{array}{c}9 \mu \mathrm{g} \text { ID } \\
\mathrm{n}=2384\end{array}$ & $\begin{array}{l}15 \mu \mathrm{IM} \\
\mathrm{n}=843\end{array}$ & $\begin{array}{c}15 \mu \mathrm{g} \text { ID } \\
\mathrm{n}=2974\end{array}$ & $\begin{array}{c}15 \mu \mathrm{g} \mathrm{IM} \\
\mathrm{n}=1458\end{array}$ \\
\hline \multicolumn{5}{|c|}{ Réactions au point d'injection (\%) } \\
\hline Douleur & 41,9 & 44,0 & 22,2 & 17,1 \\
\hline Érythème & 85,0 & 19,0 & 71,9 & 16,1 \\
\hline Enflure & 62,7 & 14,9 & 39,0 & 9,7 \\
\hline Induration & 61,5 & 19,9 & 40,9 & 12,6 \\
\hline Ecchymoses & 8,3 & 6,5 & 4,3 & 4,2 \\
\hline Prurit & 42,7 & 9,1 & 29,2 & 6,8 \\
\hline \multicolumn{5}{|c|}{ Réactions systémiques } \\
\hline Fièvre & 3,8 & 3,5 & 2,4 & 3,5 \\
\hline Maux de tête & 30,2 & 30,1 & 13,7 & 13,9 \\
\hline Malaise & 17,3 & 18,4 & 9,0 & 8,4 \\
\hline Myalgie & 22,6 & 29,5 & 10,8 & 11,2 \\
\hline Frissons & 8,7 & 8,0 & 4,1 & 4,8 \\
\hline
\end{tabular}

$\mathrm{ID}=$ intradermique; $\mathrm{IM}=$ intramusculaire

Dans l'essai mené par Arnou et ses collaborateurs(21) (phase III, adultes âgés de 18 à 64 ans), on a mené une analyse a posteriori pour déterminer s'il existait une relation directe entre les réactions au point d'injection et la séroprotection. Les taux de séroprotection ont été calculés selon quatre catégories de sujets ayant reçu le vaccin ID :

1) sujets n'ayant présenté aucune réaction au point d'injection; 2) sujets ayant présenté des réactions légères au point d'injection; 3) sujets ayant présenté au moins une réaction modérée au point d'injection, mais aucune qui n'ait été sévère; et 4) sujets ayant présenté au moins une réaction sévère au point d'injection.

Les taux de séroprotection se sont avérés plus faibles chez les sujets n'ayant présenté aucune réaction au point d'injection comparativement aux sujets des trois autres catégories (réactions légères, modérées et sévères) pour deux des trois souches. Cependant, aucune corrélation directe entre la réactogénicité au point d'injection et la séroprotection n’a été établie.

En ce qui concerne la souche $\mathrm{A} / \mathrm{H} 3 \mathrm{~N} 2$, le taux de séroprotection du groupe des sujets n'ayant présenté aucune réaction au point d'injection (93,1\%) était comparable à celui des trois autres groupes $(92,7 \%, 93,9 \%$ et $94,4 \%$ chez les sujets ayant présenté des réactions légères, modérées et sévères, respectivement). Inversement, les taux de séroprotection pour les souches $\mathrm{A} / \mathrm{H} 1 \mathrm{Nl}$ et B étaient plus faibles dans le groupe des sujets n'ayant présenté aucune réaction au point d'injection $(79,2 \%$ et $58,4 \%$, respectivement) que dans les trois autres groupes $(89,3 \%$, $85,1 \%$ et $91,2 \%$ pour la souche $\mathrm{A} / \mathrm{H} 1 \mathrm{~N} 1$ et $75,4,72,9$ 
et 74,4\% pour la souche B dans les groupes des sujets ayant présenté des réactions légères, modérées et sévères, respectivement)(21).

Il n'existe encore aucune donnée post-commercialisation sur Intanza ${ }^{\circledR}$ Pour une analyse des données post-commercialisation concernant l'usage de Vaxigrip ${ }^{\circledR}$ et d'autres VTI au Canada, veuillez vous reporter à la Déclaration du CCNI sur le VTI pour 2010-2011(5).

\section{IV.9. Contre-indications et précautions \\ $\underline{\text { Contre-indications }}$}

Intanza ${ }^{\circledR}$ ne devrait pas être administré aux personnes qui ont déjà présenté une réaction anaphylactique à une dose antérieure ou à l'un ou l'autre des composants vaccinaux. Pour obtenir plus de renseignements sur l'innocuité des vaccins et l'anaphylaxie, veuillez consulter le Guide canadien d'immunisation (GCI 2006 : http://www.phac-aspc.gc.ca/ publicat/cig-gci/index-fra.php).

\section{Précautions}

Les personnes qui présentent une hypersensibilité connue aux œufs médiée par les IgE (se manifestant par de l'urticaire, un œedème de la bouche et de la gorge, une difficulté à respirer, de l'hypotension ou un état de choc) ne devraient pas se faire vacciner chaque année contre l'influenza. Les personnes allergiques aux oufs qui présentent un risque de complications grippales devraient être évaluées par un allergologue, car la vaccination pourrait être possible après une évaluation soignée, des tests cutanés et une provocation par doses progressives ou une désensibilisation. Si une telle évaluation est impossible, il faut soupeser le risque de réaction allergique au vaccin par rapport au risque associé à l'influenza. Les recommandations pour les personnes qui ont une hypersensibilité aux œufs se retrouvent dans le Guide canadien d'immunisation(5) (GCI 2006 : http://www.phacaspc.gc.ca/publicat/cig-gci/index-fra.php).

Il faudrait demander à un expert d'évaluer les risques et les avantages de la vaccination dans le cas des personnes qui ont déjà manifesté des symptômes graves des voies respiratoires inférieures (respiration sifflante, oppression thoracique, difficulté à respirer) dans les 24 heures suivant la vaccination antigrippale, une réaction allergique apparente au vaccin ou tout autre symptôme (p. ex., constriction de la gorge, dysphagie) suscitant des craintes quant aux dangers de la revaccination. Ces conseils peuvent être fournis par les médecins hygiénistes locaux ou d'autres experts en maladies infectieuses, en allergologie/immunologie ou en santé publique.

Les sujets qui ont souffert d'un syndrome oculo-respiratoire (SOR), notamment ceux qui ont présenté des symptômes graves (rougeur bilatérale des yeux, toux, mal de gorge, voix rauque, œdème facial), mais sans symptômes des voies respiratoires inférieures, peuvent être revaccinés sans danger. Les personnes atteintes d'un SOR accompagné de symptômes des voies respiratoires inférieures devraient être évaluées par un expert, tel que décrit dans le paragraphe précédent. Les professionnels de la santé qui ne sont pas sûrs si une personne a déjà présenté un SOR ou a eu une réaction d'hypersensibilité médiée par les IgE devraient demander conseil. Compte tenu de la morbidité et de la mortalité considérable associée à l'influenza, un diagnostic d'allergie au vaccin contre l'influenza ne devrait être posé qu'après confirmation (possiblement au moyen d'un test cutané) par un spécialiste en allergologie ou en immunologie.

En général, les patients atteints d'une maladie fébrile aiguë grave ne devraient pas être vaccinés tant que leurs symptômes ne se sont pas atténués. Ceux qui souffrent d'une maladie fébrile bénigne (p. ex., infection bénigne des voies respiratoires supérieures) peuvent recevoir le vaccin. On ne devrait pas rater l'occasion d'immuniser une personne à cause du report indu de la vaccination.

On ignore s'il existe une association causale entre la vaccination antigrippale et le risque accru de récidive du syndrome de Guillain-Barré (SGB) chez les personnes ayant des antécédents de cette maladie, quelle qu'en soit la cause. Il semble prudent pour le moment d'éviter de vacciner contre l'influenza les personnes qui ont déjà présenté un SGB dans les 8 semaines suivant une vaccination antérieure.

Bien que le vaccin contre l'influenza puisse inhiber la clairance de la warfarine et de la théophylline, des études cliniques n'ont pas révélé l'existence d'un quelconque effet secondaire attribuable à ces médicaments chez les personnes qui reçoivent le vaccin antigrippal. Le traitement par un bêtabloquant n'est pas une contre-indication de 
la vaccination antigrippale. Les sujets allergiques à des substances qui n'entrent pas dans la composition du vaccin ne présentent pas de risque accru d'allergie au vaccin contre l'influenza.

Il n'existe aucune précaution particulière connue concernant l'usage d'Intanza ${ }^{\circledR}$ chez les personnes atteintes d'une maladie de la peau.

\section{IV.10. Autres considérations}

Il n'existe aucune donnée clinique concernant l'usage d'Intanza $^{\circledR}$ chez les femmes enceintes. On ignore si Intanza ${ }^{\circledR}$ est excrété dans le lait humain. Cependant, le CCNI a examiné les données disponibles sur l'innocuité de l'administration du vaccin antigrippal trivalent inactivé pendant la grossesse et il a conclu que, à ce jour, rien ne démontre que la vaccination antigrippale pose des risques pour la mère ou le fotus(5).

La morbidité maternelle grave (c.-à-d. hospitalisation) durant la saison grippale incite à recommander l'administration du VTI saisonnier aux femmes enceintes en santé, étant donné que les taux d'hospitalisation associée à l'influenza augmentent avec la durée de la grossesse après le premier trimestre. Le CCNI recommande de considérer les femmes enceintes atteintes d'une affection chronique comme un groupe devant recevoir en priorité le vaccin à n'importe quel stade de la grossesse(5).

\section{Recommandations}

Le CCNI continue de recommander de cibler les personnes qui présentent un risque élevé de complications grippales, celles qui pourraient leur transmettre l'influenza et celles qui fournissent des services communautaires essentiels pour que les programmes de vaccination puissent réduire la morbidité et la mortalité associées à l'influenza.

La liste complète des personnes auxquelles le vaccin antigrippal pour la saison 2010-2011 est recommandé est présentée au tableau 3 de la Déclaration sur le vaccin trivalent inactivé (VTI) contre l'influenza pour la saison 2010-2011 à l'adresse suivante : http://www.phac-aspc.gc.ca/publicat/ccdrrmtc/10vol36/acs-6/index-fra.php(5).
À la lumière des données probantes disponibles, le CCNI formule les recommandations suivantes concernant l'usage d'Intanza ${ }^{\circledR}$ (VTI-ID). Ces recommandations devraient être considérées en combinaison avec les recommandations existantes du CCNI concernant les personnes auxquelles le vaccin antigrippal est destiné.

\section{Le CCNI recommande d'utiliser Intanza ${ }^{\circledR}(9 \mu \mathrm{g} /$ souche) pour la prévention de l'influenza chez les adultes bien portants âgés de 18 à 59 ans. (Recommandation du CCNI de catégorie A)}

Les données des essais cliniques montrent qu'Intanza ${ }^{\circledR}$ est statistiquement non inférieur à Vaxigrip ${ }^{\circledR}$, un VTI homologué et utilisé au Canada depuis de nombreuses années et qu'il satisfait aux critères d'immunogénicité établis pour l'homologation des vaccins trivalents inactivés (VTI) contre l'influenza saisonnière.

Bien qu'Intanza ${ }^{\circledR}$ ait été associé à un nombre accru de réactions au point d'injection, les données des essais cliniques indiquent que la vaste majorité de ces réactions étaient légères et qu'elles se sont résolues en quelques jours d'elles-mêmes $(20,21)$. Aucune différence sur le plan des réactions systémiques n'a été observée entre Intanza ${ }^{\circledR}$ et un vaccin de comparaison.

La décision d'ajouter Intanza ${ }^{\circledR}$ à la liste des vaccins antigrippaux offerts aux adultes âgés de 18 à 59 ans dans le cadre des programmes publics provinciaux et territoriaux dépendra de nombreux facteurs, dont l'évaluation des coûts et des avantages et d'autres facteurs programmatiques et opérationnels locaux.

Lorsqu'ils évalueront cette question, peut-être que les provinces et territoires souhaiteront examiner les points suivants :

- L'administration d'Intanza ${ }^{\circledR}$ par micro-injection semble être intuitive et nécessiter très peu de formation. Laurent et ses collaborateurs(4) ont comparé des vaccinateurs (omnipraticiens et infirmières) ayant reçu divers niveaux de formation, allant de l'absence de formation et d'occasions de mise en pratique à la réception de directives écrites adéquates, la formation personnelle et l'obligation de respecter une marche 
à suivre détaillée. Dans tous les groupes, Intanza ${ }^{\circledR}$ a été administré adéquatement plus de $96 \%$ du temps, indépendamment de la formation reçue avant l'administration.

- Lévaluation de la perception des réactions au point d'injection d'Intanza ${ }^{\circledR}$ par les participants aux essais cliniques a révélé que $>96 \%$ de ceux-ci considéraient les réactions au point d'injection du vaccin (aussi bien ID que IM) comme ayant été « tout à fait acceptables » ou « très acceptables » et, par ailleurs, que la disposition à se faire vacciner l'année suivante et la satisfaction à l'égard du système de micro-injection ID et de la seringue IM conventionnelle étaient bonnes et qu'elles n'avaient pas été affectées par la survenue de réactions au point d'injection(29).

2. Le CCNI recommande d'utiliser Intanza ${ }^{\circledR}(9 \mu \mathrm{g} /$ souche) pour la prévention de l'influenza chez les adultes âgés de 18 à 59 ans atteints d'une affection chronique, à savoir le diabète ou une maladies cardiaque, pulmonaire ou neurologique. (Recommandation du CCNI de catégorie B)

Les données sont limitées en ce qui concerne l'usage d'Intanza ${ }^{\circledR}$ chez les adultes âgés de 18 à 59 ans atteints d'une affection chronique. Cependant, la documentation scientifique existante porte à croire qu'Intanza ${ }^{\circledR}$ (ID) est sans danger et au moins aussi immunogène qu'un vaccin antigrippal inactivé administré par voie IM chez les personnes hyporéactives atteintes d'une affection chronique. Des études approfondies sur la réponse à Intanza ${ }^{\circledR}$ selon la présence d'un déficit immunitaire ou d'une affection chronique spécifique permettraient d'étayer les recommandations visant cette population hétérogène.

3. Le CCNI recommande de considérer l'usage d'Intanza ${ }^{\circledR}$ (15 $\mu \mathrm{g} / \mathrm{souche)}$ pour la prévention de l'influenza chez les adultes âgés de 18 à 59 ans atteints d'un déficit immunitaire. (Recommandation du CCNI de catégorie I)

Il n'existe pas de preuves suffisantes (en quantité ou en qualité) pour formuler une recommandation; toutefois, d'autres facteurs pourraient influer sur la prise de décisions.
Les données sont limitées en ce qui concerne l'innocuité et l'immunogénicité d'Intanza ${ }^{\circledR}$ chez les greffés du rein. Les sujets n'ayant pas répondu à la dose de $15 \mu \mathrm{g}$ du vaccin antigrippal IM ont présenté une réponse à la préparation de $15 \mu \mathrm{g}$ d'Intanza ${ }^{\circledR} \operatorname{ID}(27)$. Les critères de l'EMEA ont été satisfaits, sauf en ce qui concerne la taille de l'échantillon. Le profil d'innocuité était semblable à celui établi dans des essais visant des sujets bien portants, où les réactions au point d'injection étaient plus nombreuses dans le groupe traité par le vaccin ID que dans celui traité par le vaccin IM et où le taux de réactions systémiques était comparable entre les deux groupes. Les sujets atteints d'un déficit immunitaire ont été exclus d'un certain nombre d'essais cliniques portant sur Intanza ${ }^{\circledR}$ (15 $\mu \mathrm{g}$ ID). Certains experts recommanderaient Intanza ${ }^{\circledR}$ (15 $\mu \mathrm{g}$ ID) pour les personnes atteintes d'un déficit immunitaire sur la base des preuves ci-dessus et des concepts théoriques de l'immunologie et de la vaccinologie.

Il est recommandé de mener des évaluations approfondies d'Intanza ${ }^{\circledR}$ dans ces populations.

4. Le CCNI recommande d'utiliser Intanza ${ }^{\circledR}(15 \mu \mathrm{g} /$ souche $)$ pour la prévention de l'influenza chez les adultes âgés de $\mathbf{6 0}$ ans et plus. (Recommandation du CCNI de catégorie A)

Les données de deux essais cliniques englobant plus de 4800 sujets montrent que la réponse immunitaire à Intanza ${ }^{\circledR}$ est statistiquement supérieure à celle induite par Vaxigrip ${ }^{\circledR}$ et qu'elle satisfait aux critères d'immunogénicité établis pour les vaccins trivalents inactivés (VTI) contre la grippe saisonnière.

Dans un essai de phase III portant sur Intanza ${ }^{\circledR}$ (14) chez des adultes âgés de 60 ans et plus, les taux de séroprotection à la suite de l'administration d'Intanza ${ }^{\circledR}$ étaient toujours plus élevés que ceux obtenus avec un vaccin IM; les écarts en points de pourcentage se situaient à $5,78(\mathrm{p}=0,0003), 5,49(\mathrm{p}<0,0001)$ et 6,60 ( $p=0,0$ 003) pour les souches A/H1N1, A/H3N2 et B, respectivement. La supériorité statistique s'est maintenue chez les sujets plus âgés, l'âge n'ayant eu aucun effet sur la supériorité après répartition des sujets dans deux groupes d'âge distincts (60-70 ans et $\geq 70$ ans). 
Aucune différence n'a été notée sur le plan de l'immunogénicité entre les sujets bien portants et ceux atteints d'une affection chronique. Les personnes atteintes d'au moins une affection chronique, à savoir le diabète ou une maladie cardiaque, pulmonaire, rénale ou neurologique, représentaient environ $65 \%$ des sujets de l'essai de phase III; cependant, les sujets atteints d'un déficit immunitaire congénital ou acquis et ceux suivant un traitement immunosuppresseur durant les six derniers mois ont été exclus.

\section{5. À l'heure actuelle, le CCNI est d'avis que les données probantes sont insuffisantes pour formuler une recommandation concernant l'usage préférentiel d'Intanza ${ }^{\circledR}$ plutôt que d'autres VTI homologués au Canada. (Recommandation du CCNI de catégorie I)}

Aucune étude n'a été publiée au sujet de l'efficacité d'Intanza ${ }^{\circledast}$. Bien que des augmentations statistiquement significatives de l'estimation ponctuelle de la séroprotection allant de 5,49 \% à 6,60\% (selon la souche) aient été notées à la suite de l'administration d'Intanza ${ }^{\circledR}$ chez des adultes âgés de 60 ans et plus, la signification clinique de cette observation sur le plan de la protection contre l'influenza confirmée en laboratoire est inconnue. 


\section{Tableau 5 : Sommaire de l'information contenue dans la présente déclaration du ccni}

le tableau suivant souligne l'information importante pour les vaccinateurs. Veuillez consulter le reste de la déclaration pour obtenir plus de détails.

\section{Objet}

a) Renseignements de base sur la maladie

(p. ex., agent, symptômes, épidémiologie)

b) Renseignements de base sur le vaccin

(p. ex., efficacité, innocuité)

\section{Sujets}

Groupes qu'il est recommandé d'immuniser
La grippe est une infection respiratoire causée par les virus de l'influenza de type A et B qui survient au Canada chaque année, généralement à la fin de l'automne et au cours de l'hiver. Les premiers symptômes de l'infection sont habituellement des maux de tête, des frissons et de la toux, suivis rapidement de fièvre, de perte d'appétit, de douleurs musculaires, de fatigue, d'écoulements nasaux, d'éternuements, de larmoiements et d'irritation de la gorge. Linfluenza peut aussi provoquer des nausées, des vomissements et la diarrhée, en particulier chez les enfants.

La plupart des personnes se rétablissent de l'influenza en l'espace d'une semaine ou de 10 jours, mais d'autres - dont celles âgées de plus de 65 ans et les adultes et enfants atteints d'une affection chronique comme le diabète et le cancer - présentent un risque accru de complications plus graves, telles que la pneumonie. Pour de plus amples renseignements sur l'influenza, veuillez consulter le lien suivant : http://www.phac-aspc. gc.ca/im/vpd-mev/influenza-fra.php.

Intanza ${ }^{\circledR}$ est un vaccin trivalent inactivé (VTI) contre l'influenza qui est administré par voie intradermique (ID). Il est offert en deux concentrations différentes, à savoir 9 et $15 \mu \mathrm{g}$ d'hémagglutinine (HA) de chaque souche du virus de l'influenza, la première concentration étant indiquée pour les adultes âgés de 18 à 59 ans et la seconde, pour les adultes âgés de 60 ans et plus.

Aucune étude n'a été publiée sur l'efficacité d'Intanza ${ }^{\circledR}$ Des essais cliniques ont montré que la réponse immunitaire à Intanza ${ }^{\circledR}$ était comparable à celle induite par un VTI administré par voie intramusculaire (IM). Intanza ${ }^{\circledR}$ satisfait et est même supérieur aux critères d'immunogénicité établis pour l'homologation des vaccins trivalents inactivés (VTI) contre l'influenza saisonnière.

Intanza ${ }^{\circledR}$ est généralement sans danger et bien toléré. Aucune différence n'a été notée sur le plan des réactions systémiques entre Intanza ${ }^{\circledR}$ et un vaccin de comparaison. Les essais cliniques ont fait ressortir un nombre accru de réactions au point d'injection, mais ces réactions étaient légères et se résolvaient d'elles-mêmes en quelques jours.

- Le CCNI recommande d'utiliser Intanza ${ }^{\circledR}$ ( $9 \mu \mathrm{g} /$ souche) pour la prévention de l'influenza chez les adultes bien portants âgés de 18 à 59 ans. (Recommandation du CCNI de catégorie A)

- Le CCNI recommande d'utiliser Intanza ${ }^{\circledR}(9 \mu \mathrm{g} /$ souche) pour la prévention de l'influenza chez les adultes âgés de 18 à 59 ans atteints d'une affection chronique, à savoir le diabète ou une maladie cardiaque, pulmonaire, rénale ou neurologique. (Recommandation du CCNI de catégorie B)

- Le CCNI recommande de considérer l'usage d'Intanza ${ }^{\circledR}$ (15 $\mu \mathrm{g} /$ souche) pour la prévention de l'influenza chez les adultes âgés de 18 à 59 ans atteints d'un déficit immunitaire. (Recommandation du CCNI de catégorie I)

- Le CCNI recommande d'utiliser Intanza ${ }^{\circledR}(15 \mu \mathrm{g} /$ souche) pour la prévention de l'influenza chez les adultes âgés de 60 ans et plus. (Recommandation du CCNI de catégorie A) 


\section{Processus}

- Dose, calendrier

- Précautions, contre-indications

- Administration concomitante d'autres vaccins

\section{But}

- «Points-conseils » que les vaccinateurs doivent souligner aux patients en expliquant les recommandations
Le vaccin antigrippal annuel est administré en une dose. La posologie recommandée

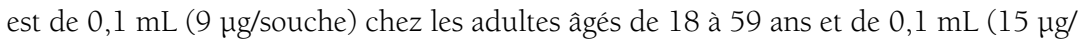
souche) chez les adultes âgés de 60 ans et plus.

Intanza ${ }^{\circledR}$ est administré par voie intradermique. Le site d'injection recommandé est la région deltoïde. Intanza ${ }^{\circledR}$ est fourni dans un système de micro-injection pour administration intradermique comprenant une seringue préremplie munie d'une micro-aiguille (1,5 mm) et un système de protection de l'aiguille destiné à recouvrir la micro-aiguille après usage.

Aucune étude n'a porté sur l'administration concomitante d'Intanza ${ }^{\circledR}$ avec d'autres vaccins. Le CCNI est d'avis qu'en général, le vaccin contre l'influenza peut être donné en même temps que d'autres vaccins, idéalement dans des membres opposés. Si les injections sont administrées dans le même membre, il faut choisir des points d'injection différents.

La vaccination est le moyen le plus efficace de prévenir l'influenza.

Chaque année, on met au point un nouveau vaccin pour conférer une protection contre de nouvelles souches du virus de l'influenza - c'est pourquoi il faut se faire vacciner contre l'influenza chaque année.

Le vaccin annuel contre l'influenza est recommandé pour l'ensemble de la population canadienne, mais particulièrement pour les personnes qui présentent un risque élevé de complications liées à l'influenza, celles qui pourraient leur transmettre l'influenza et celles qui fournissent des services communautaires essentiels.

Intanza ${ }^{\circledR}$ est sans danger et bien toléré. La présence de rougeur et d'enflure au point d'injection à la suite de l'administration d'Intanza ${ }^{\circledR}$ est courante et devrait se résoudre en quelques jours. 
Tableau 6 : Résumé des données probantes à l'appui des recommandations du CCNI

\begin{tabular}{|c|c|c|c|c|c|c|}
\hline \multicolumn{7}{|c|}{ Données probantes concernant l'immunogénicité d'Intanza ${ }^{\circledR}$} \\
\hline \multicolumn{5}{|l|}{ DÉTAILS DE L'ÉTUDE } & \multicolumn{2}{|l|}{ RÉSUMÉ } \\
\hline Étude & Vaccin & Plan d'étude & Participants & $\begin{array}{l}\text { Résumé des principales } \\
\text { observations sous forme de texte ou } \\
\text { de données }\end{array}$ & $\begin{array}{l}\text { Niveau de } \\
\text { preuve }\end{array}$ & Qualité \\
\hline $\begin{array}{l}\text { Leroux-Roels I, } \\
\text { Vets E, Freese R, } \\
\text { et coll. Seasonal } \\
\text { influenza vaccine } \\
\text { delivered by intra- } \\
\text { dermal microinjec- } \\
\text { tion: A randomised } \\
\text { controlled safety } \\
\text { and immuno- } \\
\text { genicity trial in } \\
\text { adults. Vaccine. } \\
\text { 2008;26(51):6614- } \\
6619 .(20)\end{array}$ & $\begin{array}{l}\text { Intanza } \\
\text { ( } 9 \mu \mathrm{g} \text { HA par } \\
\text { souche) }\end{array}$ & $\begin{array}{l}\text { ECR de phase II } \\
\text { ouvert } \\
\text { NCT00258934 } \\
\text { Vaccin de } \\
\text { comparaison : }_{\text {Vaxigrip }}^{\circledR} \text { IM (in- } \\
\text { tramusculaire), } \\
15 \text { Hg HA par } \\
\text { souche }\end{array}$ & $\begin{array}{l}\mathrm{N}=978 \\
(\mathrm{n}=588 \mathrm{ID}, \\
\mathrm{n}=390 \mathrm{IM}) \\
\text { Adultes bien } \\
\text { portants âgés } \\
\text { de } 18 \text { à } 57 \text { ans } \\
\text { Exclusions : } \\
\text { personnes } \\
\text { vaccinées con- } \\
\text { tre l'influenza } \\
\text { au cours des } \\
6 \text { derniers } \\
\text { mois }\end{array}$ & 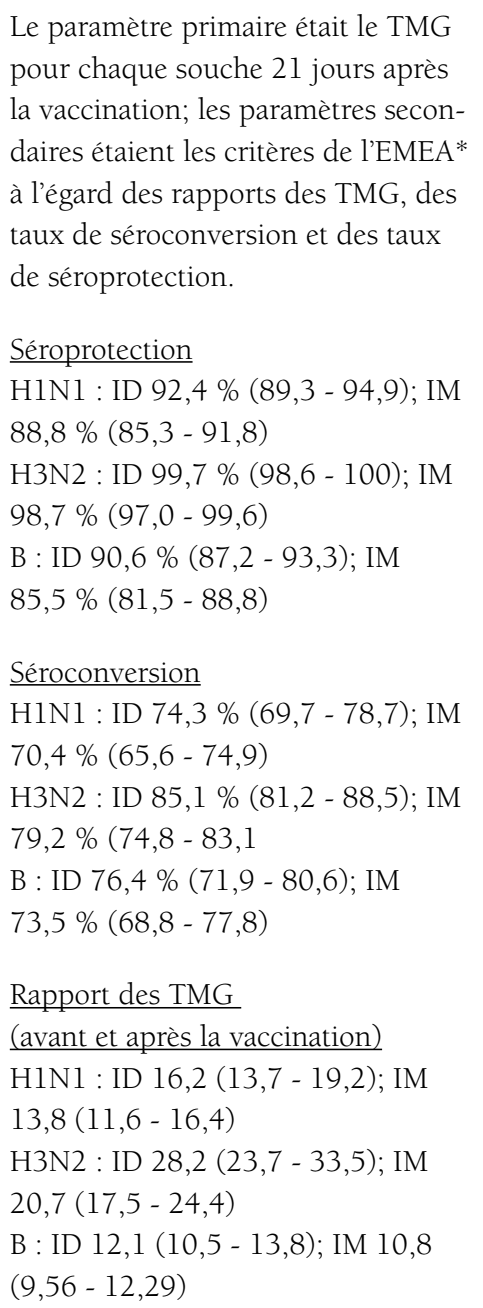 & Niveau I & Bonne \\
\hline
\end{tabular}




\begin{tabular}{|c|c|c|c|c|c|c|}
\hline \multicolumn{5}{|c|}{ Données probantes concernant l'immunogénicité d'Intanza ${ }^{\circledR}$} & & \\
\hline DÉTAILS DE L'ÉTUDE & & & & & \multicolumn{2}{|l|}{ RÉSUMÉ } \\
\hline Étude & Vaccin & Plan d'étude & Participants & $\begin{array}{l}\text { Résumé des principales } \\
\text { observations sous forme de texte ou } \\
\text { de données }\end{array}$ & $\begin{array}{l}\text { Niveau de } \\
\text { preuve }\end{array}$ & Qualité \\
\hline $\begin{array}{l}\text { Arnou R, Eavis P, } \\
\text { Pardo JR et coll., } \\
\text { Immunogenicity, } \\
\text { large scale safety } \\
\text { and lot consistency } \\
\text { of an intradermal } \\
\text { influenza vac- } \\
\text { cine in adults } \\
\text { aged 18-60 years: } \\
\text { Randomized, con- } \\
\text { trolled, phase III } \\
\text { trial. Hum vaccin. } \\
\text { 2010;6(4):346- } \\
\text { 354. (21) }\end{array}$ & $\begin{array}{l}\text { Intanza }^{\circledR} \\
\text { ( } 9 \mu \mathrm{g} \text { HA par } \\
\text { souche) }\end{array}$ & $\begin{array}{l}\text { ECR de } \\
\text { phase III, à } \\
\text { double insu } \\
\text { pour l'uniformité } \\
\text { entre les lots, ou- } \\
\text { vert pour la voie } \\
\text { d'administration } \\
\text { (ID vs IM) } \\
\text { NCT00383539 } \\
\text { Vaccin de } \\
\text { comparaison : } \\
\text { Vaxigrip }{ }^{\circledR} \text { IM (in- } \\
\text { tramusculaire), } \\
15 \mu \text { HA par } \\
\text { souche }\end{array}$ & $\begin{array}{l}\mathrm{N}=2255 \\
\text { (n = } 1803 \mathrm{ID} ; \\
\text { trois lots mis } \\
\text { en commun, } \\
\mathrm{n}=452 \mathrm{IM} \text { ) } \\
\text { Adultes bien } \\
\text { portants âgés } \\
\text { de } 18 \text { à } 60 \text { ans } \\
\text { Exclusions : } \\
\text { personnes } \\
\text { vaccinées con- } \\
\text { tre l'influenza } \\
\text { au cours des } \\
6 \text { derniers } \\
\text { mois }\end{array}$ & 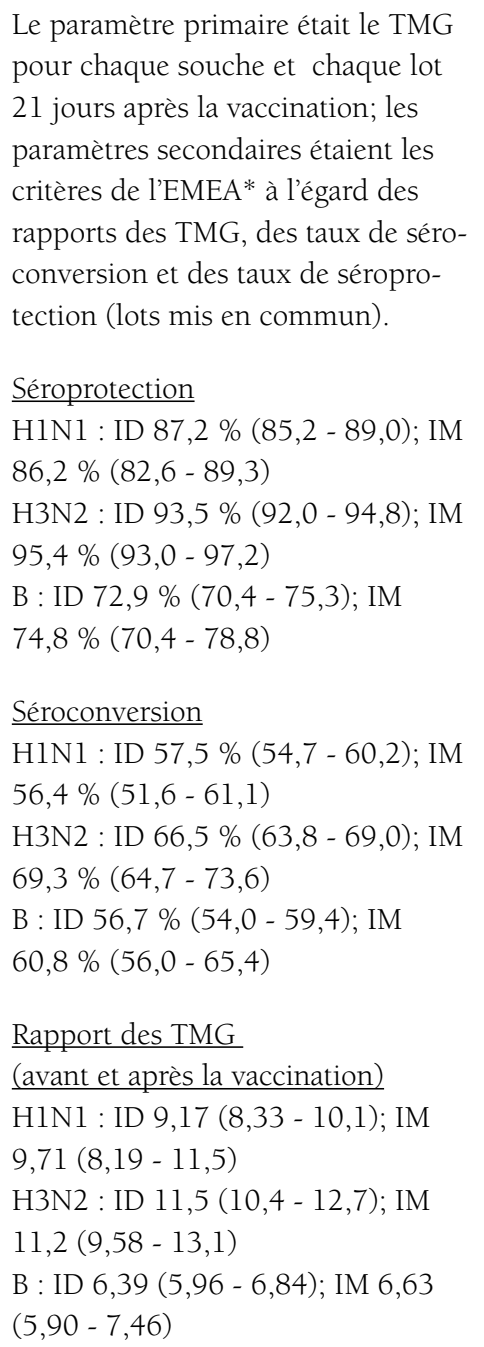 & Niveau I & Bonne \\
\hline
\end{tabular}




\begin{tabular}{|c|c|c|c|c|c|c|}
\hline \multicolumn{7}{|c|}{ Données probantes concernant l'immunogénicité d'Intanza ${ }^{\circledR}$} \\
\hline \multicolumn{5}{|l|}{ DÉTAILS DE L'ÉTUDE } & \multicolumn{2}{|l|}{ RÉSUMÉ } \\
\hline Étude & Vaccin & Plan d'étude & Participants & $\begin{array}{l}\text { Résumé des principales } \\
\text { observations sous forme de texte ou } \\
\text { de données }\end{array}$ & $\begin{array}{l}\text { Niveau de } \\
\text { preuve }\end{array}$ & Qualité \\
\hline $\begin{array}{l}\text { Holland D, Booy } \\
\text { R, De Looze F, et } \\
\text { al. Intradermal in- } \\
\text { fluenza vaccine ad- } \\
\text { ministered using a } \\
\text { new microinjection } \\
\text { system produces } \\
\text { superior immuno- } \\
\text { genicity in elderly } \\
\text { adults: a random- } \\
\text { ized controlled } \\
\text { trial. J Infect Dis. } \\
\text { 2008;198(5):650- } \\
658 .(13)\end{array}$ & $\begin{array}{l}\text { Intanza }^{\circledR} \\
\text { (15 et } 21 \mu g \\
\text { HA par } \\
\text { souche) }\end{array}$ & $\begin{array}{l}\text { ECR de phase II; } \\
\text { à double insu } \\
\text { pour la dose ID, } \\
\text { ouvert pour la } \\
\text { voie IM } \\
\text { NCT00296829 } \\
\text { Vaccin de } \\
\text { comparaison : } \\
\text { Vaxigrip }{ }^{\circledR} \text { IM (in- } \\
\text { tramusculaire), } \\
15 \text { H HA par } \\
\text { souche }\end{array}$ & $\begin{array}{l}\mathrm{N}=1107 \\
(\mathrm{n}=370 \mathrm{ID} \\
15 \mu \mathrm{g}, \mathrm{n}= \\
369 \mathrm{ID} 21 \mu \mathrm{g}, \\
\mathrm{n}=368 \mathrm{IM} \\
15 \mu \mathrm{g}) \\
\text { Adultes âgés } \\
\text { de } 60 \text { à } 85 \text { ans } \\
\text { dont l'état } \\
\text { de santé est } \\
\text { stable } \\
\text { Exclusions : } \\
\text { personnes } \\
\text { vaccinées con- } \\
\text { tre l'influenza } \\
\text { au cours des } \\
\text { six derniers } \\
\text { mois }\end{array}$ & 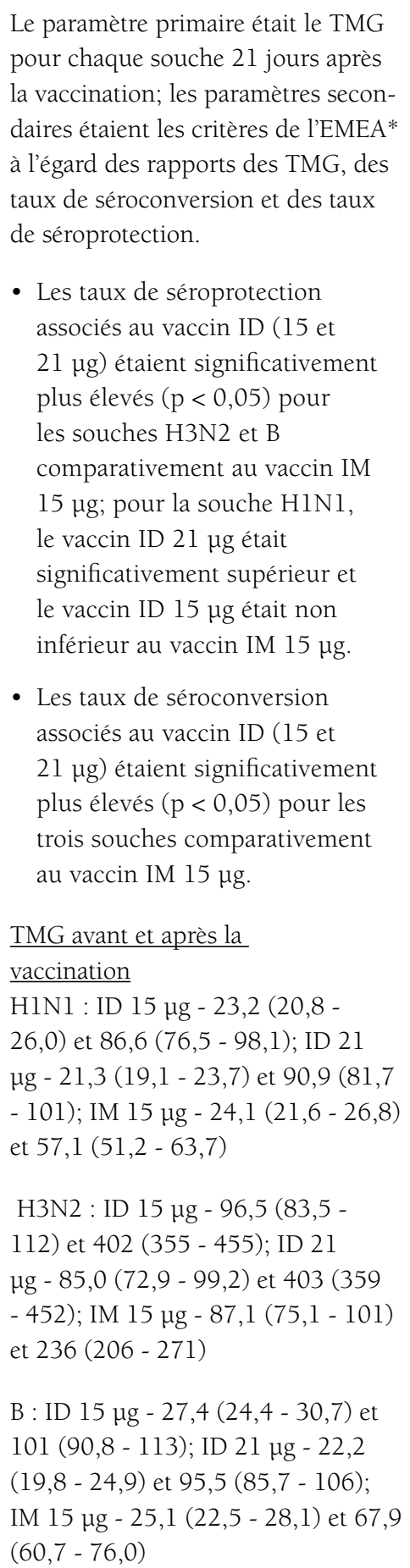 & Niveau I & Bonne \\
\hline
\end{tabular}




\begin{tabular}{|c|c|c|c|c|c|c|}
\hline \multicolumn{7}{|c|}{ Données probantes concernant l'immunogénicité d'Intanza ${ }^{\circledR}$} \\
\hline \multicolumn{5}{|l|}{ DÉTAILS DE L'ÉTUDE } & \multicolumn{2}{|l|}{ RÉSUMÉ } \\
\hline Étude & Vaccin & Plan d'étude & Participants & $\begin{array}{l}\text { Résumé des principales } \\
\text { observations sous forme de texte ou } \\
\text { de données }\end{array}$ & $\begin{array}{l}\text { Niveau de } \\
\text { preuve }\end{array}$ & Qualité \\
\hline $\begin{array}{l}\text { Arnou R, Icardi } \\
\text { G, De Decker M, } \\
\text { et coll. Intrader- } \\
\text { mal influenza } \\
\text { vaccine for older } \\
\text { adults: a random- } \\
\text { ized controlled } \\
\text { multicenter phase } \\
\text { III study. Vaccine. } \\
\text { 2009;27(52):7304- } \\
7312 .(14)\end{array}$ & $\begin{array}{l}\text { Intanza }^{\circledR} \\
(15 \mu g \text { HA } \\
\text { par souche) }\end{array}$ & 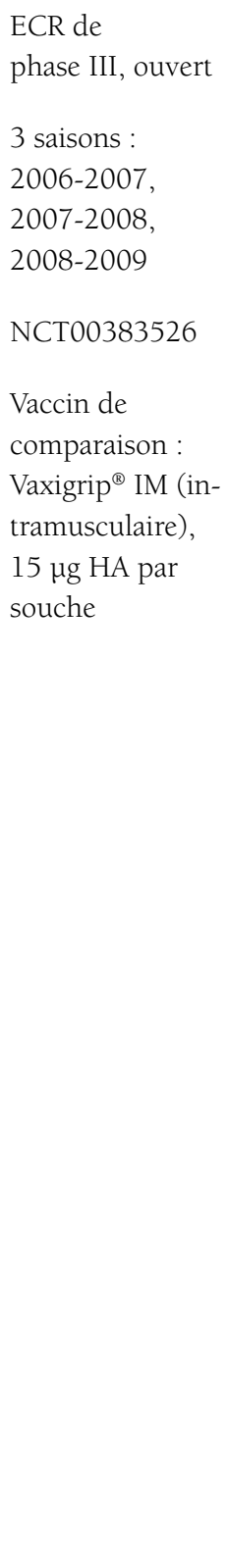 & $\begin{array}{l}\mathrm{N}=3707 \\
(\mathrm{n}=2618 \mathrm{ID}, \\
\mathrm{n}=1089 \mathrm{IM} \\
\text { pour la pre- } \\
\text { mière saison, } \\
\text { randomisation } \\
\text { selon un rap- } \\
\text { port } 1: 1 \text { pour } \\
\text { chaque saison } \\
\text { suivante) } \\
\text { Adultes âgés } \\
\text { de } \geq 60 \text { ans } \\
\text { dont l'état } \\
\text { de santé est } \\
\text { stable }\end{array}$ & 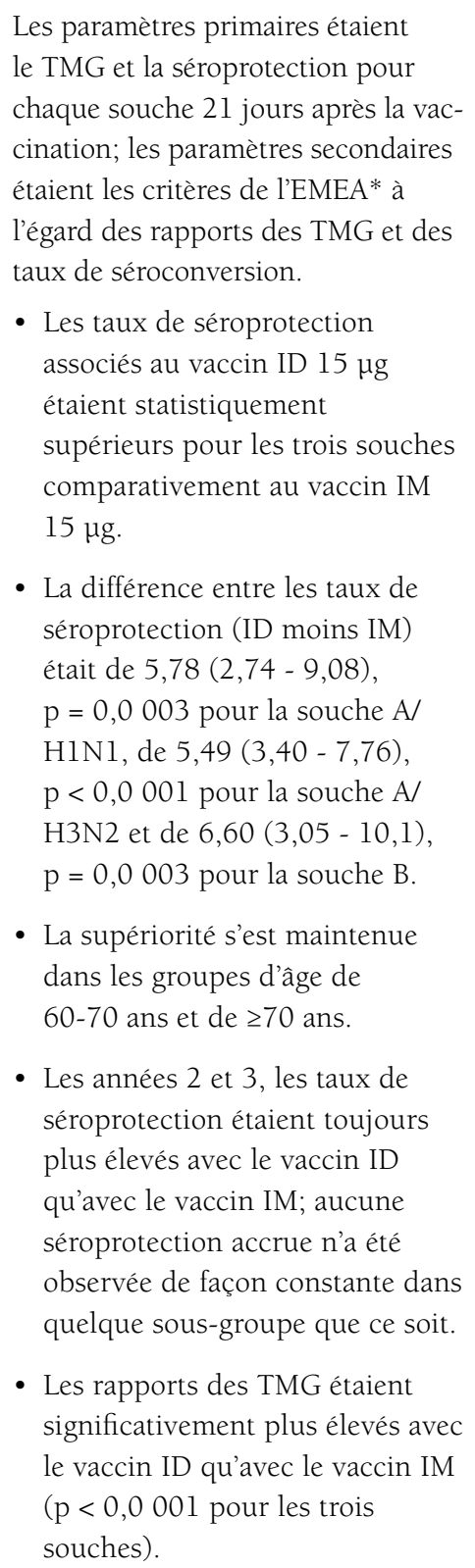 & Niveau I & Bonne \\
\hline
\end{tabular}




\begin{tabular}{|c|c|c|c|c|c|c|}
\hline \multicolumn{7}{|c|}{ Données probantes concernant l'immunogénicité d'Intanza ${ }^{\circledR}$} \\
\hline \multicolumn{5}{|l|}{ DÉTAILS DE L'ÉTUDE } & \multicolumn{2}{|l|}{ RÉSUMÉ } \\
\hline Étude & Vaccin & Plan d'étude & Participants & $\begin{array}{l}\text { Résumé des principales } \\
\text { observations sous forme de texte ou } \\
\text { de données }\end{array}$ & $\begin{array}{l}\text { Niveau de } \\
\text { preuve }\end{array}$ & Qualité \\
\hline $\begin{array}{l}\text { Beran J, Ambro- } \\
\text { zaitis A, Laiskonis } \\
\text { A, et coll. Intrader- } \\
\text { mal influenza vac- } \\
\text { cination of healthy } \\
\text { adults using a } \\
\text { new microinjec- } \\
\text { tion system: a } \\
\text { 3-year randomised } \\
\text { controlled safety } \\
\text { and immunoge- } \\
\text { nicity trial. BMC } \\
\text { Med. 2009;7:13. } \\
\text { 10.1186/1741- } \\
7015-7-13 .(19)\end{array}$ & $\begin{array}{l}\text { Intanza }^{\circledR} \\
(3,6,9 \text { et } \\
15 \mu \mathrm{gA} \\
\text { par souche })\end{array}$ & $\begin{array}{l}\text { ECR de phase II } \\
\text { (étude visant } \\
\text { à établir } \\
\text { l'intervalle de la } \\
\text { dose) } \\
3 \text { saisons } \\
\text { NCT00703651 } \\
\text { Vaccin de } \\
\text { comparaison : } \\
\text { Vaxigrip }{ }^{\circledR} \text { IM (in- } \\
\text { tramusculaire), } \\
15 \text { Hg HA par } \\
\text { souche }\end{array}$ & $\begin{array}{l}\mathrm{N}=1150 \\
18-57 \text { ans }\end{array}$ & 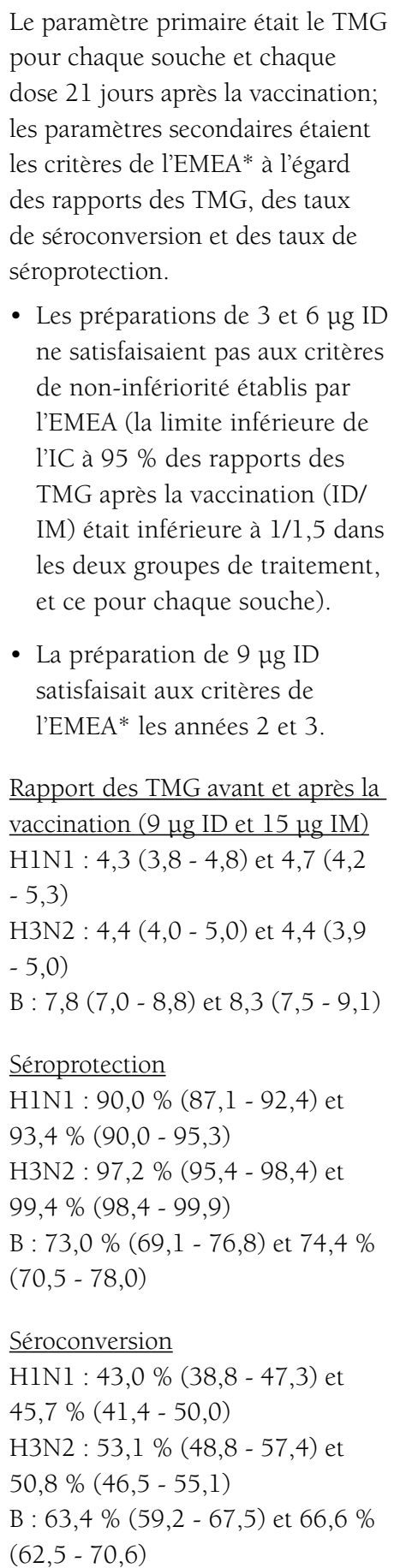 & Niveau I & Bonne \\
\hline
\end{tabular}




\begin{tabular}{|c|c|c|c|c|c|c|}
\hline \multicolumn{5}{|c|}{ Données probantes concernant l'immunogénicité d'Intanza ${ }^{\circledR}$} & & \\
\hline DÉTAILS DE L'ÉTUDE & & & & & \multicolumn{2}{|l|}{ RÉSUMÉ } \\
\hline Étude & Vaccin & Plan d'étude & Participants & $\begin{array}{l}\text { Résumé des principales } \\
\text { observations sous forme de texte ou } \\
\text { de données }\end{array}$ & $\begin{array}{l}\text { Niveau de } \\
\text { preuve }\end{array}$ & Qualité \\
\hline $\begin{array}{l}\text { Van Damme P, } \\
\text { Arnou R, Kafeja F, } \\
\text { et coll. Evaluation } \\
\text { of non-inferiority } \\
\text { of intradermal } \\
\text { versus adjuvanted } \\
\text { seasonal influ- } \\
\text { enza vaccine using } \\
\text { two serological } \\
\text { techniques: a } \\
\text { randomised } \\
\text { comparative study. } \\
\text { BMC Infect Dis. } \\
\text { 2010;10:134. (22) }\end{array}$ & $\begin{array}{l}\text { Intanza }^{\circledR} \\
\text { (15 } \mu \mathrm{g} \mathrm{HA} \\
\text { par souche) }\end{array}$ & $\begin{array}{l}\text { ECR de phase } \\
\text { III, ouvert } \\
\text { NCT00554333 } \\
\text { Vaccin de } \\
\text { comparaison : } \\
\text { Fluad }{ }^{\circledR} \text { IM (à } \\
\text { virion frag- } \\
\text { menté, conten- } \\
\text { ant l'adjuvant } \\
\text { MF59C.1) } \\
\text { 2007-2008 }\end{array}$ & $\begin{array}{l}\mathrm{N}=795 \\
(\mathrm{n}=398 \mathrm{ID}, \\
\mathrm{n}=397 \mathrm{IM}) \\
\text { Adultes âgés } \\
\text { de } \geq 65 \text { ans) }\end{array}$ & 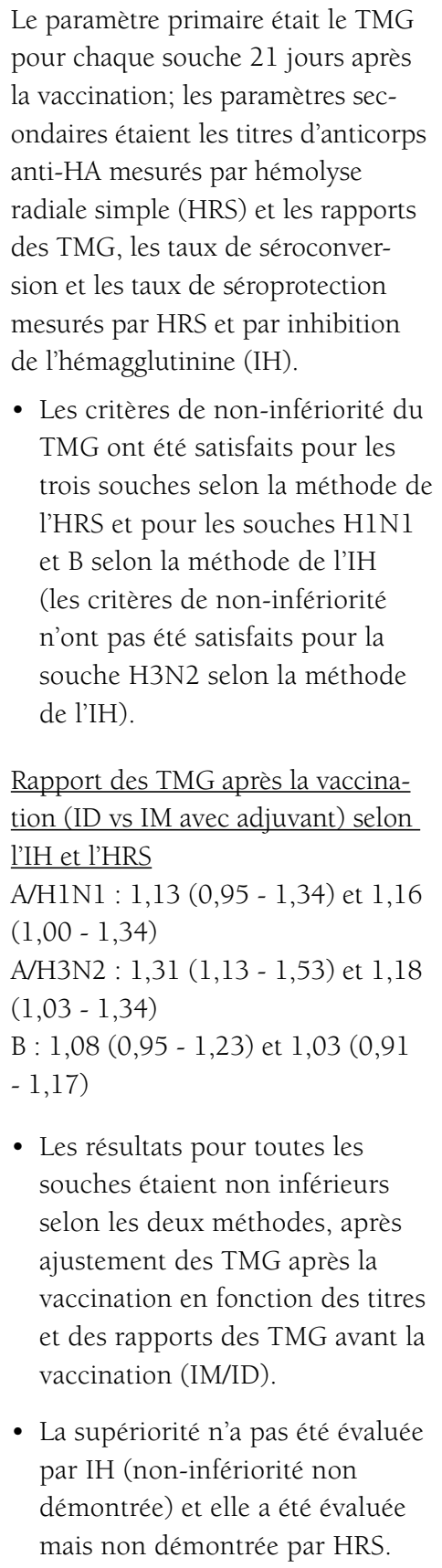 & Niveau I & Bonne \\
\hline
\end{tabular}




\begin{tabular}{|c|c|c|c|c|c|c|}
\hline \multicolumn{5}{|c|}{ Données probantes concernant l'immunogénicité d'Intanza ${ }^{\circledR}$} & \multirow{2}{*}{\multicolumn{2}{|c|}{$\begin{array}{l} \\
\text { RÉSUMÉ }\end{array}$}} \\
\hline \multicolumn{5}{|l|}{ DÉTAILS DE L'ÉTUDE } & & \\
\hline Étude & Vaccin & Plan d'étude & Participants & $\begin{array}{l}\text { Résumé des principales } \\
\text { observations sous forme de } \\
\text { texte ou de données }\end{array}$ & $\begin{array}{l}\text { Niveau de } \\
\text { preuve }\end{array}$ & Qualité \\
\hline $\begin{array}{l}\text { Leroux-Roels I, Vets } \\
\text { E, Freese R, et coll. } \\
\text { Seasonal influenza } \\
\text { vaccine delivered } \\
\text { by intradermal } \\
\text { microinjection: A } \\
\text { randomised con- } \\
\text { trolled safety and } \\
\text { immunogenicity trial } \\
\text { in adults. Vaccine. } \\
\text { 2008;26(51):6614- } \\
6619 .(20)\end{array}$ & $\begin{array}{l}\text { Intanza }^{\circledR} \\
(9 \mu \mathrm{g} \mathrm{HA} \\
\text { par souche) }\end{array}$ & $\begin{array}{l}\text { Phase II } \\
\text { NCT00258934 }\end{array}$ & 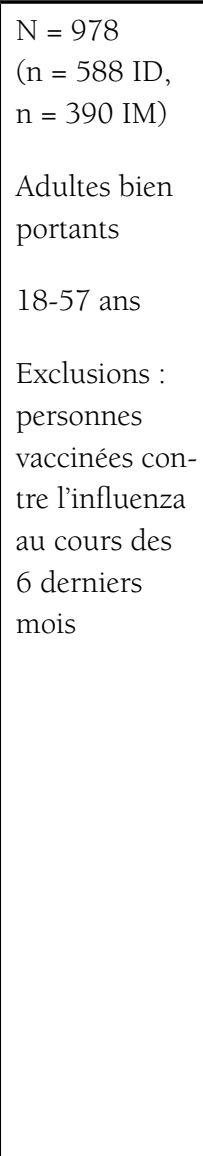 & $\begin{array}{l}\text { - Les taux d'érythème, } \\
\text { d'induration et } \\
\text { d'enflure étaient plus } \\
\text { élevés à la suite de } \\
\text { l'administration d'Intanza }{ }^{\circledR} \\
\text { ID (intradermique) } \\
\text { comparativement à Vaxigrip }{ }^{\circledR} \\
\text { IM (intramusculaire). } \\
\text { - Érythème >5 cm signalé chez } \\
\text { 9,6\% vs } 0,8 \% \text { et érythème } \\
\text { durant >4 jours observé chez } \\
44 \% \text { vs } 1,3 \% \text { des sujets } \\
\text { traités par le vaccin ID et IM, } \\
\text { respectivement } \\
\text { - La proportion d'événements } \\
\text { indésirables systémiques } \\
\text { (EIS) était comparable, sauf } \\
\text { en ce qui a trait à la myalgie, } \\
\text { qui a touché un plus grand } \\
\text { nombre de receveurs du } \\
\text { vaccin IM ( } 29,4 \text { vs } 19,7 \% \text { ). } \\
7 \text { EIS observés; } 6 \text { sans } \\
\text { relation et } 1 \text { cas d'abcès } \\
\text { périamygdalien, peu } \\
\text { susceptible d'être lié à la } \\
\text { vaccination }\end{array}$ & Niveau I & Bonne \\
\hline
\end{tabular}




\begin{tabular}{|c|c|c|c|c|c|c|}
\hline \multicolumn{7}{|c|}{ Données probantes concernant l'immunogénicité d'Intanza ${ }^{\circledR}$} \\
\hline \multicolumn{5}{|l|}{ DÉTAILS DE L'ÉTUDE } & \multicolumn{2}{|l|}{ RÉSUMÉ } \\
\hline Étude & Vaccin & Plan d'étude & Participants & $\begin{array}{l}\text { Résumé des principales } \\
\text { observations sous forme de } \\
\text { texte ou de données }\end{array}$ & $\begin{array}{l}\text { Niveau de } \\
\text { preuve }\end{array}$ & Qualité \\
\hline $\begin{array}{l}\text { Arnou R, Eavis P, } \\
\text { Pardo JR, et coll. } \\
\text { Immunogenicity, } \\
\text { large scale safety } \\
\text { and lot consistency } \\
\text { of an intradermal } \\
\text { influenza vaccine in } \\
\text { adults aged 18-60 } \\
\text { years: Randomized, } \\
\text { controlled, phase } \\
\text { III trial. Hum vaccin. } \\
\text { 2010;6(4):346-354. } \\
(21)\end{array}$ & $\begin{array}{l}\text { Intanza }^{\circledR} \\
(9 \mu \mathrm{g} \mathrm{HA} \\
\text { par souche })\end{array}$ & $\begin{array}{l}\text { ECR de phase III, } \\
\text { à double insu } \\
\text { pour l'uniformité } \\
\text { entre les lots, ou- } \\
\text { vert pour la voie } \\
\text { d'administration } \\
\text { (ID vs IM) } \\
\text { NCT00383539 }\end{array}$ & $\begin{array}{l}\mathrm{N}=2255 \\
\text { (n = } 1803 \text { ID; } \\
\text { trois lots mis } \\
\text { en commun, } \\
\mathrm{n}=452 \mathrm{IM} \text { ) } \\
\text { Adultes bien } \\
\text { portants âgés } \\
\text { de } 18 \text { à } 60 \text { ans } \\
\text { Exclusions : } \\
\text { personnes } \\
\text { vaccinées con- } \\
\text { tre l'influenza } \\
\text { au cours des } \\
6 \text { derniers } \\
\text { mois }\end{array}$ & 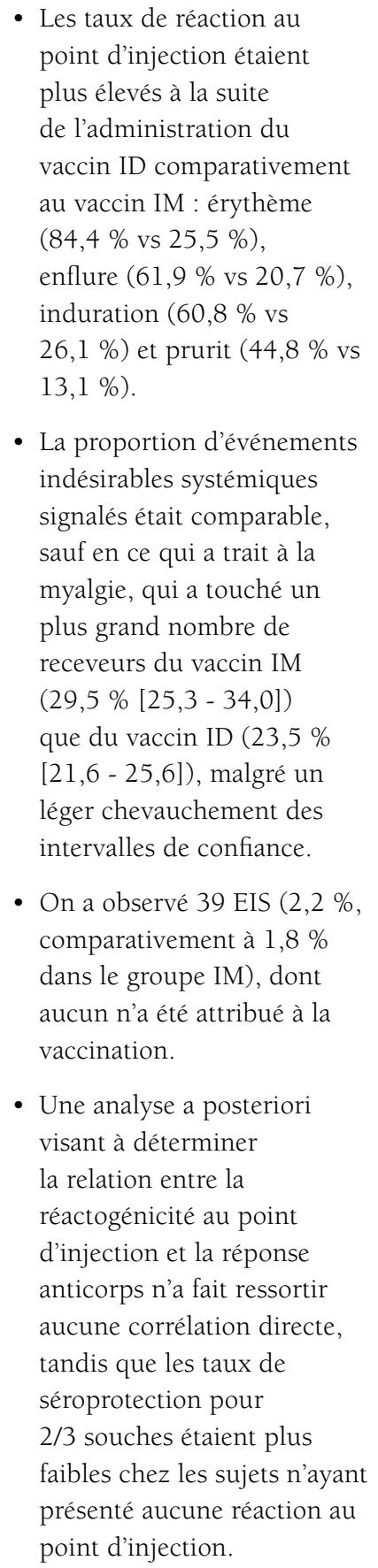 & Niveau I & Good \\
\hline
\end{tabular}




\begin{tabular}{|c|c|c|c|c|c|c|}
\hline \multicolumn{7}{|c|}{ Données probantes concernant l'immunogénicité d'Intanza ${ }^{\circledR}$} \\
\hline \multicolumn{5}{|l|}{ DÉTAILS DE L'ÉTUDE } & \multicolumn{2}{|l|}{ RÉSUMÉ } \\
\hline Étude & Vaccin & Plan d'étude & Participants & $\begin{array}{l}\text { Résumé des principales } \\
\text { observations sous forme de } \\
\text { texte ou de données }\end{array}$ & \begin{tabular}{|l} 
Niveau de \\
preuve
\end{tabular} & Qualité \\
\hline $\begin{array}{l}\text { Holland D, Booy } \\
\text { R, De Looze F, et } \\
\text { coll. Intradermal } \\
\text { influenza vaccine } \\
\text { administered using a } \\
\text { new microinjection } \\
\text { system produces } \\
\text { superior immuno- } \\
\text { genicity in elderly } \\
\text { adults: a random- } \\
\text { ized controlled } \\
\text { trial. J Infect Dis. } \\
\text { 2008;198(5):650- } \\
658 . \text { (13) }\end{array}$ & $\begin{array}{l}\text { Intanza }{ }^{\circledR}(15 \\
\text { et } 21 \mu \mathrm{HA} \\
\text { par souche) }\end{array}$ & $\begin{array}{l}\text { ECR de phase II; } \\
\text { à double insu } \\
\text { pour la dose ID, } \\
\text { ouvert pour la } \\
\text { voie IM } \\
\text { NCT00296829 } \\
\text { Vaccin de } \\
\text { comparaison : }_{\text {Vaxigrip }^{\circledR}}\end{array}$ & $\begin{array}{l}\mathrm{N}=1107 \\
(\mathrm{n}=370 \\
\mathrm{ID} 15 \mu \mathrm{g}, \\
\mathrm{n}=369 \\
\mathrm{ID} 21 \mu \mathrm{g}, \\
\mathrm{n}=368 \\
\mathrm{IM} 15 \mu \mathrm{g}) \\
\text { Adultes âgés } \\
\text { de } 60 \text { à } 85 \text { ans } \\
\text { dont l'état } \\
\text { de santé est } \\
\text { stable } \\
\text { Exclusions : } \\
\text { personnes } \\
\text { vaccinées con- } \\
\text { tre l'influenza } \\
\text { au cours des } \\
6 \text { derniers } \\
\text { mois }\end{array}$ & $\begin{array}{l}\text { - L'incidence de l'érythème } \\
\text { ( } 78,8 \% \text { et } 77,7 \% \text { vs } \\
19,1 \% \text { ), de l'enflure (62,3\% } \\
\text { et } 58,2 \% \text { vs } 13,4 \% \text { ), de } \\
\text { l'induration }(64,6 \% \text { et } \\
65,2 \% \text { vs } 16,7 \% \text { et du } \\
\text { prurit }(27,7 \% \text { et } 32,1 \% \text { vs } \\
8,7 \% \text { ) était plus élevée avec } \\
\text { le vaccin ID (15 et } 21 \mu g \text {, } \\
\text { respectivement) qu'avec le } \\
\text { vaccin IM } 15 \mu \mathrm{gg} \text {. } \\
\text { - Lincidence des réactions } \\
\text { systémiques était comparable } \\
\text { d'un groupe à l'autre. }\end{array}$ & Niveau I & Bonne \\
\hline
\end{tabular}




\begin{tabular}{|c|c|c|c|c|c|c|}
\hline \multicolumn{5}{|c|}{ Données probantes concernant l'immunogénicité d'Intanza ${ }^{\circledR}$} & \multirow{2}{*}{\multicolumn{2}{|c|}{ RÉSUMÉ }} \\
\hline \multicolumn{5}{|l|}{ DÉTAILS DE L'ÉTUDE } & & \\
\hline Étude & Vaccin & Plan d'étude & Participants & $\begin{array}{l}\text { Résumé des principales } \\
\text { observations sous forme de } \\
\text { texte ou de données }\end{array}$ & $\begin{array}{l}\text { Niveau de } \\
\text { preuve }\end{array}$ & Qualité \\
\hline $\begin{array}{l}\text { Arnou R, Icardi G, } \\
\text { De Decker M, et } \\
\text { coll. Intradermal } \\
\text { influenza vaccine for } \\
\text { older adults: a ran- } \\
\text { domized controlled } \\
\text { multicenter phase } \\
\text { III study. Vaccine. } \\
\text { 2009;27(52):7304- } \\
\text { 7312. (14) }\end{array}$ & $\begin{array}{l}\text { Intanza }^{\circledR} \\
(15 \mu \mathrm{g} \mathrm{HA} \\
\text { par souche })\end{array}$ & $\begin{array}{l}\text { ECR de phase III, } \\
\text { ouvert } \\
3 \text { saisons : } \\
\text { 2006-2007, } \\
\text { 2007-2008, } \\
\text { 2008-2009 } \\
\text { NCT00383526 } \\
\text { Vaccin de } \\
\text { comparaison : }_{\text {Vaxigrip }^{\circledR}}\end{array}$ & $\begin{array}{l}\mathrm{N}=3707 \\
(\mathrm{n}=2618 \mathrm{ID}, \\
\mathrm{n}=1089 \mathrm{IM} \\
\text { pour la pre- } \\
\text { mière saison, } \\
\text { randomisation } \\
\text { selon un rap- } \\
\text { port } 1: 1 \text { pour } \\
\text { chaque saison } \\
\text { suivante) }\end{array}$ & 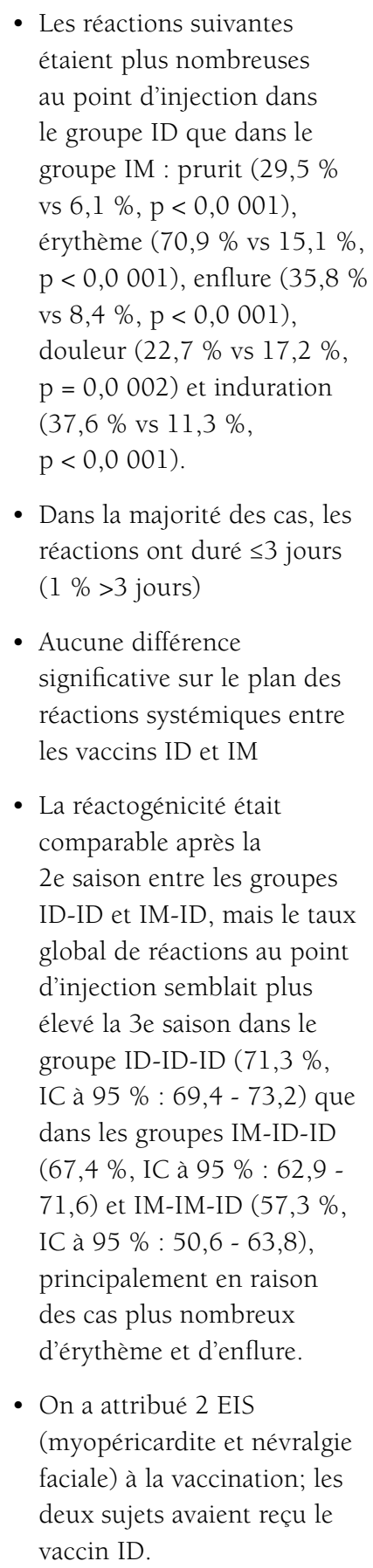 & Niveau I & Bonne \\
\hline
\end{tabular}




\begin{tabular}{|c|c|c|c|c|c|c|}
\hline \multicolumn{7}{|c|}{ Données probantes concernant l'immunogénicité d'Intanza ${ }^{\circledR}$} \\
\hline \multicolumn{5}{|l|}{ DÉTAILS DE L'ÉTUDE } & \multicolumn{2}{|l|}{ RÉSUMÉ } \\
\hline Étude & Vaccin & Plan d'étude & Participants & $\begin{array}{l}\text { Résumé des principales } \\
\text { observations sous forme de } \\
\text { texte ou de données }\end{array}$ & $\begin{array}{l}\text { Niveau de } \\
\text { preuve }\end{array}$ & Qualité \\
\hline $\begin{array}{l}\text { Van Damme P, } \\
\text { Arnou R, Kafeja F, } \\
\text { et coll. Evaluation } \\
\text { of non-inferiority of } \\
\text { intradermal versus } \\
\text { adjuvanted seasonal } \\
\text { influenza vaccine } \\
\text { using two sero- } \\
\text { logical techniques: } \\
\text { a randomised } \\
\text { comparative study. } \\
\text { BMC Infect Dis. } \\
\text { 2010;10:134. (22) }\end{array}$ & Intanza $^{\circledast}$ & $\begin{array}{l}\text { ECR de phase III, } \\
\text { ouvert } \\
\text { NCT00554333 } \\
\text { Vaccin de com- } \\
\text { paraison : Fluad } \\
\text { IM (à virion } \\
\text { fragmenté, con- } \\
\text { tenant l'adjuvant } \\
\text { MF59C.1) }\end{array}$ & 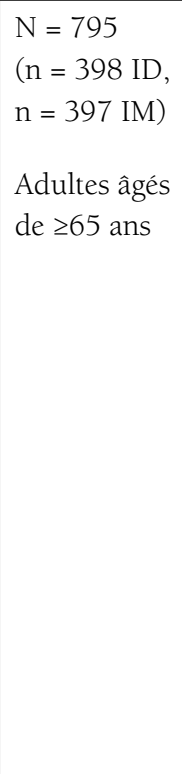 & $\begin{array}{l}\text { - Les taux d'érythème (63,1\% } \\
\text { vs } 13,4 \% \text { ), d'enflure } \\
\text { - ( } 34,2 \% \text { vs } 8,6 \%) \text {, } \\
\text { d'induration ( } 32,9 \% \text { vs } \\
10,6 \% \text { ) et de prurit ( } 28,1 \% \\
\text { vs } 6,5 \% \text { ) étaient plus élevés } \\
\text { dans le groupe ID. } \\
\text { - L'incidence des réactions } \\
\text { systémiques était comparable } \\
\text { d'un groupe à l'autre. } \\
\text { - Des } 6 \text { événements } \\
\text { indésirables graves survenus, } \\
2 \text { ont été attribués à la } \\
\text { vaccination (pneumonie } \\
\text { dans le groupe ID et zona } \\
\text { facial dans le groupe IM avec } \\
\text { adjuvant). }\end{array}$ & Niveau I & Bonne \\
\hline
\end{tabular}




\begin{tabular}{|c|c|c|c|c|c|c|}
\hline \multicolumn{5}{|c|}{ Données probantes concernant l'immunogénicité d'Intanza ${ }^{\circledR}$} & \multirow{2}{*}{\multicolumn{2}{|c|}{ RÉSUMÉ }} \\
\hline \multicolumn{5}{|l|}{ DÉTAILS DE L'ÉTUDE } & & \\
\hline Étude & Vaccin & Plan d'étude & Participants & $\begin{array}{l}\text { Résumé des principales } \\
\text { observations sous forme de } \\
\text { texte ou de données }\end{array}$ & $\begin{array}{l}\text { Niveau de } \\
\text { preuve }\end{array}$ & Qualité \\
\hline $\begin{array}{l}\text { Beran J, Ambrozaitis } \\
\text { A, Laiskonis A, et } \\
\text { coll. Intradermal in- } \\
\text { fluenza vaccination } \\
\text { of healthy adults } \\
\text { using a new micro- } \\
\text { injection system: a } \\
\text { 3-year randomised } \\
\text { controlled safety } \\
\text { and immunoge- } \\
\text { nicity trial. BMC } \\
\text { Med. 2009;7:13. } \\
\text { 10.1186/1741- } \\
7015-7-13 .(19)\end{array}$ & $\begin{array}{l}\text { Intanza }^{\circledR} \\
(3,6,9 \text { ou } \\
15 \mu g \mathrm{HA} \\
\text { par souche })\end{array}$ & $\begin{array}{l}\text { ECR de phase II } \\
\text { (visant à établir la } \\
\text { dose) } \\
3 \text { années (an- } \\
\text { née } 1 \text { : } 3 \text { vs } 6 \mu \mathrm{g} \\
\text { ID; année } 2 \text { : } \\
9 \mu \text { ID vs } 15 \mu \mathrm{g} \\
\text { IM; année } 3 \text { : } \\
9 \mu \text { ID vs } 15 \mu \mathrm{g} \\
\text { IM) } \\
\text { NCT00703651 } \\
\text { Vaccin de } \\
\text { comparaison : } \\
\text { Vaxigrip }{ }^{\circledR}\end{array}$ & $\begin{array}{l}\mathrm{N}=1150 \\
18-57 \text { ans }\end{array}$ & 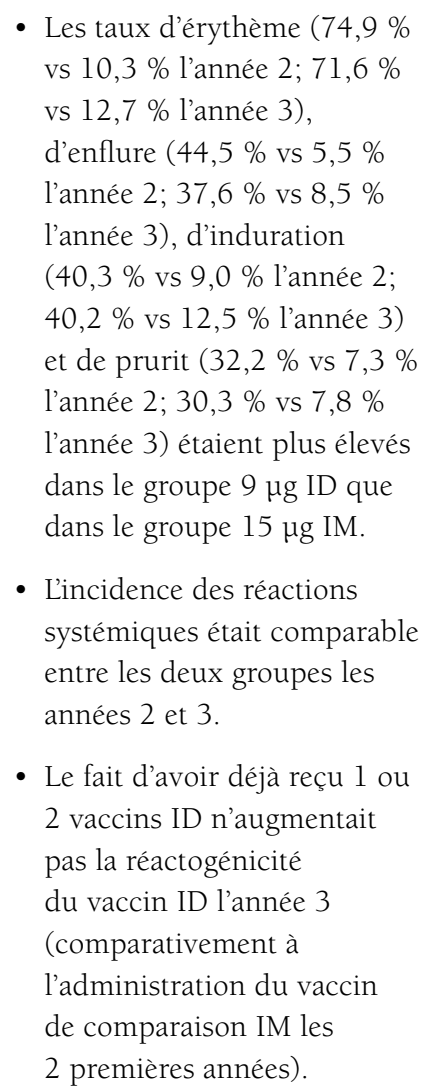 & Niveau I & Bonne \\
\hline
\end{tabular}




\begin{tabular}{|c|c|c|c|c|c|c|}
\hline \multicolumn{7}{|c|}{ Données probantes concernant l'immunogénicité d'Intanza ${ }^{\circledR}$} \\
\hline \multicolumn{5}{|l|}{ DÉTAILS DE L'ÉTUDE } & \multicolumn{2}{|l|}{ RÉSUMÉ } \\
\hline Étude & Vaccin & Plan d'étude & Participants & $\begin{array}{l}\text { Résumé des principales } \\
\text { observations sous forme } \\
\text { de texte ou de données }\end{array}$ & $\begin{array}{l}\text { Niveau de } \\
\text { preuve }\end{array}$ & Qualité \\
\hline $\begin{array}{l}\text { Manuel O, Humar } \\
\text { A, Chen MH, et coll. } \\
\text { Immunogenicity } \\
\text { and safety of an in- } \\
\text { tradermal boosting } \\
\text { strategy for vaccina- } \\
\text { tion against influ- } \\
\text { enza in lung trans- } \\
\text { plant recipients. } \\
\text { Am J Transplant. } \\
2007 ; 7(11): 2567- \\
2572 .(23)\end{array}$ & $\begin{array}{l}\text { Vaxigrip }^{\circledR} \\
15 \mu g \text { IM, } \\
\text { puis } 3 \mu g \text { ID } \\
\text { (technique } \\
\text { de Mantoux) } \\
4 \text { semaines } \\
\text { plus tard }\end{array}$ & \begin{tabular}{|l} 
Étude \\
observation- \\
nelle
\end{tabular} & $\begin{array}{l}\mathrm{N}=60 \\
\text { Âge moyen : } 47,3 \text { ans } \\
\text { Adultes greffés du pou- } \\
\text { mon ( }>3 \text { mois depuis la } \\
\text { greffe) }\end{array}$ & $\begin{array}{l}\text { - } 63 \% \text { (38/60) des } \\
\text { sujets ont présenté } \\
\text { une réponse à la } \\
\text { vaccination IM. } \\
\text { - Les TMG ont } \\
\text { augmenté pour } \\
\text { chacun des trois } \\
\text { antigènes du vaccin } \\
\text { après la première } \\
\text { dose (p < } 0,001) \text {. } \\
\text { - Aucune } \\
\text { augmentation notable } \\
\text { des titres n'a été } \\
\text { observée après la } \\
\text { dose de rappel pour } \\
\text { les trois antigènes. } \\
\text { - Parmi les sujets } \\
\text { n'ayant pas répondu } \\
\text { à la dose initiale du } \\
\text { vaccin, 3/22 (13,6 \%) } \\
\text { ont répondu à la } \\
\text { dose de rappel } \\
\text { intradermique } \\
\text { (p = 0,14). } \\
\text { - Lutilisation de } \\
\text { basiliximab a été } \\
\text { associée à une } \\
\text { réponse positive } \\
\text { (p = 0,024). }\end{array}$ & Niveau II-3 & $\begin{array}{l}\text { Bonne } \\
\text { Petite étude } \\
\text { observa- } \\
\text { tionnelle } \\
\text { non contrô- } \\
\text { lée }\end{array}$ \\
\hline
\end{tabular}




\begin{tabular}{|c|c|c|c|c|c|c|}
\hline \multicolumn{7}{|c|}{ Données probantes concernant l'immunogénicité d'Intanza ${ }^{\circledR}$} \\
\hline \multicolumn{5}{|l|}{ DÉTAILS DE L'ÉTUDE } & \multicolumn{2}{|l|}{ RÉSUMÉ } \\
\hline Étude & Vaccin & Plan d'étude & Participants & $\begin{array}{l}\text { Résumé des principales } \\
\text { observations sous forme } \\
\text { de texte ou de données }\end{array}$ & $\begin{array}{l}\text { Niveau de } \\
\text { preuve }\end{array}$ & Qualité \\
\hline $\begin{array}{l}\text { Jo YM, Song JY, } \\
\text { Hwang IS, et } \\
\text { coll. Dose spar- } \\
\text { ing strategy with } \\
\text { intradermal influ- } \\
\text { enza vaccination in } \\
\text { patients with solid } \\
\text { cancer. J Med Virol. } \\
\text { 2009;81(4):722- } \\
727 .(24)\end{array}$ & $\begin{array}{l}\text { Fluarix }^{\circledR} \\
15 \mu g \text { IM, } \\
7,5 \mu \mathrm{g} \mathrm{ID} \\
\text { (technique de } \\
\text { Mantoux) }\end{array}$ & ECR & 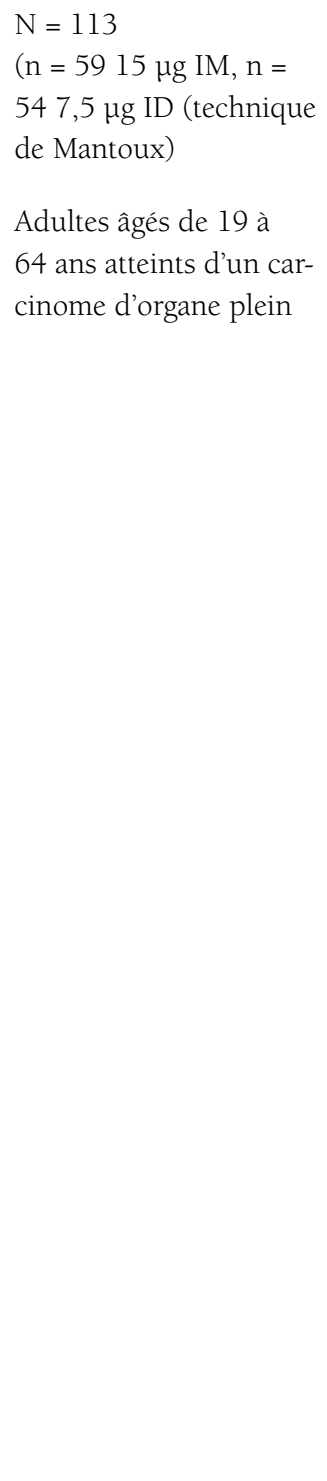 & 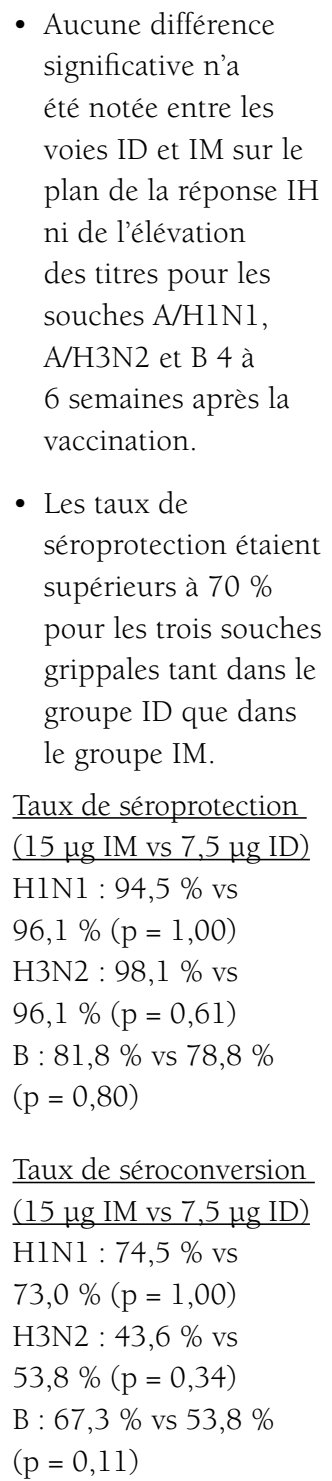 & Niveau I & $\begin{array}{l}\text { Bonne } \\
\text { Absence de } \\
\text { groupe de } \\
\text { comparai- } \\
\text { son traité } \\
\text { par } 7,5 \mu g \\
\text { IM }\end{array}$ \\
\hline
\end{tabular}

\footnotetext{
${ }^{1}$ Harris RP, Helfand M, Woolf SH, et al. Current methods of the US Preventive Services Task Force: a review of the process. Am J Prev Med 2001;20:21-35.
} 


\begin{tabular}{|c|c|c|c|c|c|c|}
\hline \multicolumn{7}{|c|}{ Données probantes concernant l'immunogénicité d'Intanza ${ }^{\circledR}$} \\
\hline \multicolumn{5}{|l|}{ DÉTAILS DE L'ÉTUDE } & \multicolumn{2}{|l|}{ RÉSUMÉ } \\
\hline Étude & Vaccin & Plan d'étude & Participants & $\begin{array}{l}\text { Résumé des principales } \\
\text { observations sous forme } \\
\text { de texte ou de données }\end{array}$ & $\begin{array}{l}\text { Niveau de } \\
\text { preuve }\end{array}$ & Qualité \\
\hline $\begin{array}{l}\text { Chuaychoo B, } \\
\text { Wongsurakiat P, } \\
\text { Nana A, et coll. } \\
\text { The immunogenic- } \\
\text { ity of intradermal } \\
\text { influenza vac- } \\
\text { cination in COPD } \\
\text { patients. Vaccine. } \\
\text { 2010;28(24):4045- } \\
4051 .(25)\end{array}$ & $\begin{array}{l}\text { VTI (Merieux } \\
\text { Biological } \\
\text { Products, } \\
\text { Thaillande) } \\
15 \mu \mathrm{g} \text { IM, } \\
6 \mu \mathrm{g} \text { ID } \\
\text { (technique } \\
\text { de Mantoux; } \\
\text { demi-dose } \\
\text { administrée } \\
\text { dans chaque } \\
\text { bras) }\end{array}$ & $\begin{array}{l}\text { ECR, sans } \\
\text { aveugle }\end{array}$ & $\begin{array}{l}\mathrm{N}=156 \\
\text { Adultes âgés de } 36 \text { à } \\
91 \text { ans } \\
\text { Diagnostic de MPOC } \\
\text { et rapport VEMS/CV } \\
<0,70\end{array}$ & 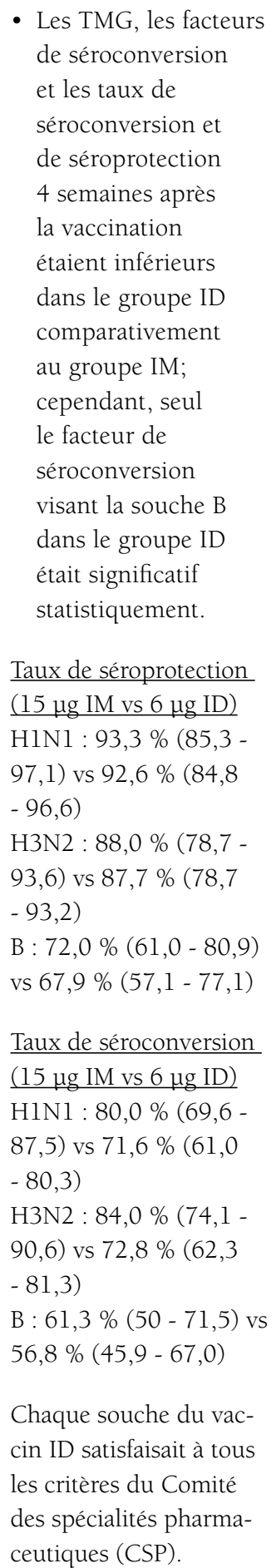 & Niveau I & $\begin{array}{l}\text { Passable } \\
\text { Sans aveu- } \\
\text { gle; aucun } \\
\text { groupe de } \\
\text { comparai- } \\
\text { son portant } \\
\text { sur l'injec- } \\
\text { tion ID } \\
\text { dans un } \\
\text { même site }\end{array}$ \\
\hline
\end{tabular}




\begin{tabular}{|c|c|c|c|c|c|c|}
\hline \multicolumn{7}{|c|}{ Données probantes concernant l'immunogénicité d'Intanza ${ }^{\circledR}$} \\
\hline \multicolumn{5}{|l|}{ DÉTAILS DE L'ÉTUDE } & \multicolumn{2}{|l|}{ RÉSUMÉ } \\
\hline Étude & Vaccin & Plan d'étude & Participants & $\begin{array}{l}\text { Résumé des principales } \\
\text { observations sous forme } \\
\text { de texte ou de données }\end{array}$ & $\begin{array}{l}\text { Niveau de } \\
\text { preuve }\end{array}$ & Qualité \\
\hline $\begin{array}{l}\text { Gelinck LB, van } \\
\text { den Bemt BJ, } \\
\text { Marijt WA, et coll. } \\
\text { Intradermal influ- } \\
\text { enza vaccination in } \\
\text { immunocompro- } \\
\text { mized patients is } \\
\text { immunogenic and } \\
\text { feasible. Vaccine. } \\
\text { 2009;27(18):2469- } \\
2474 .(26)\end{array}$ & $\begin{array}{l}\text { VTI (Influ- } \\
\text { vac }^{\text {MD }} \text { ) } \\
2005-2006 \\
15 \mu g \text { IM, } \\
3 \mu g \text { ID } \\
\text { (technique de } \\
\text { Mantoux) }\end{array}$ & ECR, ouvert & $\begin{array}{l}\mathrm{N}=197 \\
\text { Adultes atteints d'un } \\
\text { déficit immunitaire } \\
\text { (n = } 81: \text { infection à } \\
\text { VIH, } \mathrm{n}=50 \text { : polyarth- } \\
\text { rite rhumatoïde traitée } \\
\text { par des inhibiteurs du } \\
\text { TNF (facteur de nécrose } \\
\text { tumorale), n = } 26: \\
\text { greffe de cellules sou- } \\
\text { ches hématopoiétiques } \\
\text { (GCSH)) } \\
+41 \text { témoins bien } \\
\text { portants }\end{array}$ & $\begin{array}{l}\text { - Les titres après la } \\
\text { vaccination étaient } \\
\text { semblables entre } \\
\text { les receveurs du } \\
\text { vaccin ID et du } \\
\text { vaccin IM dans les } \\
\text { quatre groupes. } \\
\text { - Dans l'ensemble, les } \\
\text { titres les plus élevés } \\
\text { ont été observés } \\
\text { chez les témoins } \\
\text { bien portants, suivis } \\
\text { dans l'ordre des } \\
\text { sujets traités par des } \\
\text { inhibiteurs du TNF, } \\
\text { des sujets infectés } \\
\text { par le VIH et des } \\
\text { receveurs de GCSH, } \\
\text { aussi bien dans le } \\
\text { groupe ID que dans } \\
\text { le groupe IM. } \\
\text { - Les réactions au } \\
\text { point d'injection, } \\
\text { qui étaient moins } \\
\text { nombreuses et plus } \\
\text { légères chez les sujets } \\
\text { atteints d'un déficit } \\
\text { immunitaire que } \\
\text { chez les sujets bien } \\
\text { portants à la suite } \\
\text { de l'administration } \\
\text { du vaccin ID, } \\
\text { permettaient de } \\
\text { prédire une réponse à } \\
\text { au moins un des trois } \\
\text { antigènes (p < } 0,05 \text { ). }\end{array}$ & Niveau I & $\begin{array}{l}\text { Passable } \\
\text { Sans } \\
\text { aveugle }\end{array}$ \\
\hline
\end{tabular}




\begin{tabular}{|c|c|c|c|c|c|c|}
\hline \multicolumn{7}{|c|}{ Données probantes concernant l'immunogénicité d'Intanza ${ }^{\circledR}$} \\
\hline \multicolumn{5}{|l|}{ DÉTAILS DE L'ÉTUDE } & \multicolumn{2}{|l|}{ RÉSUMÉ } \\
\hline Étude & Vaccin & Plan d'étude & Participants & $\begin{array}{l}\text { Résumé des principales } \\
\text { observations sous forme } \\
\text { de texte ou de données }\end{array}$ & $\begin{array}{l}\text { Niveau de } \\
\text { preuve }\end{array}$ & Qualité \\
\hline $\begin{array}{l}\text { Morelon E, Noble } \\
\text { CP, Daoud S, et } \\
\text { coll. Immunogenic- } \\
\text { ity and safety of } \\
\text { intradermal influ- } \\
\text { enza vaccination } \\
\text { in renal transplant } \\
\text { patients who were } \\
\text { non-responders to } \\
\text { conventional influ- } \\
\text { enza vaccination. } \\
\text { Vaccine. 2010 Oct } \\
4 ; 28(42): 6885-90 . \\
(27)\end{array}$ & $\begin{array}{l}\text { Vaxigrip }^{\circledR} \text {, } \\
2006-2007, \\
15 \mu \mathrm{g} \mathrm{IM} \\
\text { vs } \\
\text { Intanza }^{\circledR} \text {, } \\
15 \mu \mathrm{g} \mathrm{ID}\end{array}$ & $\begin{array}{l}\text { Essai contrôlé } \\
\text { randomisé } \\
\text { s'inscrivant } \\
\text { dans le cadre } \\
\text { d'une étude } \\
\text { descriptive } \\
\text { plus vaste }\end{array}$ & $\begin{array}{l}\mathrm{N}=62 \text { sujets n'ayant } \\
\text { pas répondu au vaccin } \\
\text { initial, randomisés selon } \\
\text { un rapport } 1: 1 \text { dans les } \\
\text { groupes ID et IM } \\
\text { Létude plus vaste englo- } \\
\text { bait } 201 \text { adultes âgés de } \\
18 \text { à } 60 \text { ans (l'intervalle } \\
\text { des âges dans le groupe } \\
\text { des sujets n'ayant pas } \\
\text { répondu allait de } 40 \text { à } \\
56 \text { ans). }\end{array}$ & 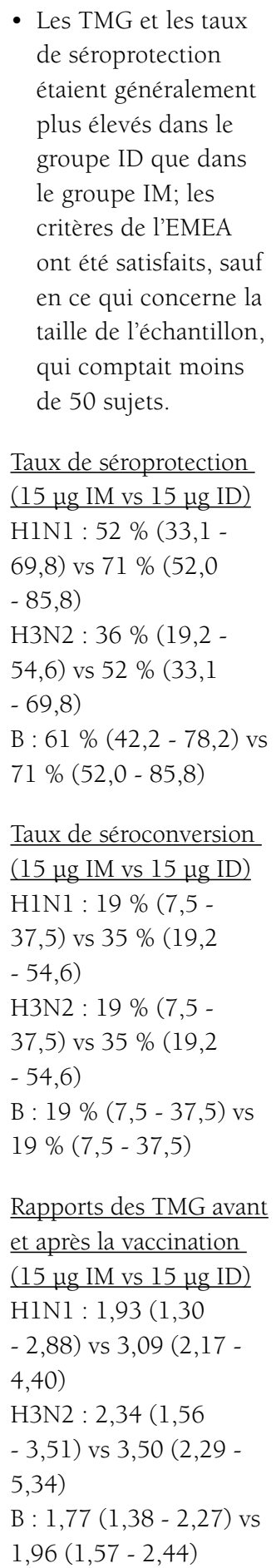 & Niveau I & $\begin{array}{l}\text { Passable } \\
\text { Petite } \\
\text { étude, sans } \\
\text { aveugle, } \\
\text { sans groupe } \\
\text { témoin } \\
\text { constitué de } \\
\text { sujets bien } \\
\text { portants }\end{array}$ \\
\hline
\end{tabular}




\section{Tableau 7 : Niveaux de preuve selon le modèle de recherche}

\begin{tabular}{l|l}
\hline I & Données probantes provenant d'un ou de plusieurs essais cliniques comparatifs randomisés. \\
\hline II-1 & Données probantes provenant d'un ou de plusieurs essais cliniques comparatifs sans randomisation. \\
\hline \hline II-2 & $\begin{array}{l}\text { Données probantes provenant d'études analytiques de cohortes ou cas/témoins, de préférence de plus d'un centre ou groupe de } \\
\text { recherche utilisant des indicateurs cliniques de résultats de l'efficacité d'un vaccin. }\end{array}$ \\
\hline II-3 & $\begin{array}{l}\text { Données probantes provenant d'études de plusieurs séries chronologiques avec ou sans intervention. Les résultats spectaculaires } \\
\text { obtenus dans un contexte non contrôlé (comme les résultats de l'introduction de la pénicilline dans les années 1940) pourraient } \\
\text { aussi être considérés comme faisant partie de ce type de données probantes. }\end{array}$ \\
\hline III & $\begin{array}{l}\text { Opinions d'experts respectés fondées sur l'expérience clinique, des études descriptives et des études de cas ou des rapports de } \\
\text { comités d'experts. }\end{array}$ \\
\hline
\end{tabular}

Tableau 8 : Cote de qualité des preuves (validité interne)

\begin{tabular}{l||l}
\hline Bonne & Étude (notamment les méta-analyses ou les recensions systématiques) répondant bien à tous les critères propres à la méthodologie*. \\
\hline Passable & $\begin{array}{l}\text { Étude (notamment les méta-analyses ou les recensions systématiques) ne répondant pas (ou du moins pas clairement) à au } \\
\text { moins un critère propre à la méthodologie* mais n'ayant pas de « lacune majeure » connue. }\end{array}$ \\
\hline Mauvaise & $\begin{array}{l}\text { Étude (notamment les méta-analyses ou les recensions systématiques) ayant au moins une « lacune majeure » propre à la mé- } \\
\text { thodologie* ou une accumulation de lacunes moins importantes ne permettant pas de formuler des recommandations à partir } \\
\text { des résultats de l'étude. }\end{array}$ \\
\hline \hline * Les critères généraux propres à la méthodologie sont décrits dans l'article de Harris et coll., 20011. \\
\hline
\end{tabular}

\section{Tableau 9 : Recommandations du CCNI concernant l'immunisation - Catégories}

\begin{tabular}{l|l}
\hline \hline A & Les données probantes sont suffisantes pour recommander l'immunisation. \\
\hline B & Les données probantes sont acceptables pour recommander l'immunisation. \\
\hline C & $\begin{array}{l}\text { Les données probantes existantes sont contradictoires et ne permettent pas de faire une recommandation pour ou contre } \\
\text { l'immunisation; cependant, d'autres facteurs peuvent influencer la prise de décisions. }\end{array}$ \\
\hline D & Les données probantes sont acceptables pour déconseiller l'immunisation. \\
\hline E & Les données probantes sont suffisantes pour déconseiller l'immunisation. \\
\hline \hline I & $\begin{array}{l}\text { Les données probantes sont insuffisantes (en quantité ou en qualité) pour formuler une recommandation; cependant, d'autres } \\
\text { facteurs peuvent influencer la prise de décisions. }\end{array}$ \\
\hline \hline
\end{tabular}

\footnotetext{
${ }^{1}$ Harris RP, Helfand M, Woolf SH, et al. Current methods of the US Preventive Services Task Force: a review of the process. Am J Prev Med 2001;20:21-35.
} 


\section{Liste des abréviations}

BCG Bacille Calmette-Guérin

CCNI Comité consultatif national de l'immunisation

EMEA Agence européenne des médicaments

HA Hémagglutinine

HRS Hémolyse radiale simple

IC Intervalle de confiance

ID Intradermique

IgE Immunoglobuline E

IH Inhibition de l'hémagglutinine

IM Intramusculaire

$\mathrm{mL} \quad$ Millilitres

mm Millimètre

OMS Organisation mondiale de la Santé

pH1N1 Virus pandémique de l'influenza H1N1

RMTC Relevé des maladies transmissibles au Canada

SGB Syndrome de Guillain-Barré

SOR Syndrome oculo-respiratoire

TMG Titre moyen géométrique

VTI Vaccin antigrippal trivalent inactivé

VTI-ID Vaccin antigrippal trivalent inactivé intradermique

ug $\quad$ Microgramme 


\section{Références}

1. Sanofi Pasteur. Intanza ${ }^{\circledR}$ : vaccin antigrippal (virion fragmenté, inactivé), Toronto, Canada : Sanofi Pasteur Limited, 2010. Accessible en ligne à : http:// www.sanofipasteur.ca/sanofi-pasteur2/sp-medial SP_CA/FR/75/1215/415\%20416\%20INTANZA\%20 R0-0510\%20Fr.pdf

2. Lambert PH, Laurent PE. Intradermal vaccine delivery: Will new delivery systems transform vaccine administration? Vaccine. 2008 Jun 19;26(26):3197-208.

3. Nicolas JF, Guy B. Intradermal, epidermal and transcutaneous vaccination: From immunology to clinical practice. Expert Rev Vaccines. 2008 Oct; 7(8):1201-14.

4. Laurent PE, Bonnet S, Alchas P, et coll. Evaluation of the clinical performance of a new intradermal vaccine administration technique and associated delivery system. Vaccine. 2007 Dec 17;25(52):8833-42.

5. Comité consultatif national de l'immunisation (CCNI). Déclaration sur le vaccin trivalent inactivé (VTI) contre la grippe pour la saison 2010-2011, Relevé des maladies transmissibles au Canada, 2010, 36(DCC-6) : 1-49.

6. Jefferson T, Di Pietrantonj C, Rivetti A, et coll. Vaccines for preventing influenza in healthy adults. Cochrane Database Syst Rev. 2010 Jul 7;(7)(7):CD001269.

7. Jefferson T, Di Pietrantonj C, Al-Ansary LA, et coll. Vaccines for preventing influenza in the elderly. Cochrane Database Syst Rev. 2010 Feb 17;(2) (2):CD004876.

8. Hobson D, Curry RL, Beare AS, et coll. The role of serum haemagglutination-inhibiting antibody in protection against challenge infection with influenza A2 and B viruses. J Hyg (Lond). 1972 Dec;70(4):767-77.

9. Plotkin SA. Immunologic correlates of protection induced by vaccination. Pediatr Infect Dis J. 2001 Jan;20(1):63-75.
10. Hannoun C, Megas F, Piercy J. Immunogenicity and protective efficacy of influenza vaccination. Virus Res. $2004 \mathrm{Jul} ; 103(1-2): 133-8$.

11. Coudeville L, Bailleux F, Riche B, et coll. Relationship between haemagglutination-inhibiting antibody titres and clinical protection against influenza: Development and application of a bayesian random-effects model. BMC Med Res Methodol. 2010 Mar 8;10:18.

12. Coudeville L, Andre P, Bailleux F, et coll. A new approach to estimate vaccine efficacy based on immunogenicity data applied to influenza vaccines administered by the intradermal or intramuscular routes. Hum Vaccin. 2010 Oct 8;6(10).

13. Holland D, Booy R, De Looze F, et coll. Intradermal influenza vaccine administered using a new microinjection system produces superior immunogenicity in elderly adults: A randomized controlled trial. J Infect Dis. 2008 Sep 1;198(5):650-8.

14. Arnou R, Icardi G, De Decker M, et coll. Intradermal influenza vaccine for older adults: A randomized controlled multicenter phase III study. Vaccine. 2009 Dec 9;27(52):7304-12.

15. Pearton M, Kang SM, Song JM, et coll. Changes in human langerhans cells following intradermal injection of influenza virus-like particle vaccines. PLoS One. 2010 Aug 25;5(8):e12410.

16. Kupper TS, Fuhlbrigge RC. Immune surveillance in the skin: Mechanisms and clinical consequences. Nat Rev Immunol. 2004 Mar;4(3):211-22.

17. Allenspach EJ, Lemos MP, Porrett PM, et coll. Migratory and lymphoid-resident dendritic cells cooperate to efficiently prime naive CD4 T cells. Immunity. 2008 Nov 14:29(5):795-806.

18. Committee for Proprietary Medicinal Products (CHMP). Note for guidance on harmonisation of requirements for influenza vaccines. London, UK: European Medicines Agency (EMEA); 1997. 
19. Beran J, Ambrozaitis A, Laiskonis A, et coll. Intradermal influenza vaccination of healthy adults using a new microinjection system: A 3-year randomised controlled safety and immunogenicity trial. BMC Med. 2009 Apr $2 ; 7: 13$.

20. Leroux-Roels I, Vets E, Freese R, et coll. Seasonal influenza vaccine delivered by intradermal microinjection: A randomised controlled safety and immunogenicity trial in adults. Vaccine. $2008 \mathrm{Dec}$ 2;26(51):6614-9.

21. Arnou R, Eavis P, Pardo JR, et coll. Immunogenicity, large scale safety and lot consistency of an intradermal influenza vaccine in adults aged 18-60 years: Randomized, controlled, phase III trial. Hum vaccin. 2010 Apr;6(4):346-54.

22. Van Damme P, Arnou R, Kafeja F, et coll. Evaluation of non-inferiority of intradermal versus adjuvanted seasonal influenza vaccine using two serological techniques: A randomised comparative study. BMC Infect Dis. 2010;10:134.

23. Manuel O, Humar A, Chen MH, et coll. Immunogenicity and safety of an intradermal boosting strategy for vaccination against influenza in lung transplant recipients. Am J Transplant. 2007 Nov;7(11):2567-72.

\section{Footnote}

1. Harris RP, Helfand M, Woolf SH, et al. Current methods of the US Preventive Services Task Force: a review of the process. Am J Prev Med 2001;20:21-35.
24. Jo YM, Song JY, Hwang IS, et coll. Dose sparing strategy with intradermal influenza vaccination in patients with solid cancer. J Med Virol. 2009 Apr;81(4):722-7.

25. Chuaychoo B, Wongsurakiat P, Nana A, et coll. The immunogenicity of intradermal influenza vaccination in COPD patients. Vaccine. 2010 May 28;28(24):4045-51.

26. Gelinck LB, van den Bemt BJ, Marijt WA, et coll. Intradermal influenza vaccination in immunocompromized patients is immunogenic and feasible. Vaccine. 2009 Apr 21;27(18):2469-74.

27. Morelon E, Noble CP, Daoud S, et coll. Immunogenicity and safety of intradermal influenza vaccination in renal transplant patients who were non-responders to conventional influenza vaccination. Vaccine. 2010 Oct 4;28(42):6885-90.

28. Sanofi Pasteur. Subanalysis of phase III Intanza ${ }^{\circledR}$ clinical trial of adults 60 years of age and over. In press 2010 .

29. Reygrobellet C, Viala-Danten M, Meunier J, et coll. Perception and acceptance of intradermal influenza vaccination: Patient reported outcomes from phase 3 clinical trials. Hum vaccin. 2010 Apr;6(4):336-45. 